\title{
Centrifugal Organization of Direction Preferences in the Cat's Lateral Suprasylvian Visual Cortex and Its Relation to Flow Field Processing
}

\author{
Josef P. Rauschecker, Michael W. von Grünau, and Carmen Poulin ${ }^{\mathrm{b}}$ \\ Max-Planck-Institut für biologische Kybernetik, 7400 Tübingen, Federal Republic of Germany
}

The cerebral cortex of the cat contains between 1 and 2 dozen representations of the visual field with different functional specializations. Six visual field maps lie along both banks of the suprasylvian sulcus, lateral and anterior to the visual areas in the occipital cortex. We have studied singleunit receptive field properties and their global organization across the visual field in $\mathbf{2}$ of these lateral suprasylvian areas, PMLS (essentially the Clare-Bishop area) and PLLS.

Most neurons in PMLS and PLLS display selectivity for the direction of a light stimulus moving across their receptive fields with various degrees of directional tuning. We have used light spots of different size and velocity projected on a tangent screen in order to determine the direction preference of cells in these 2 areas. A strong tendency was found for neurons to respond best to centrifugal directions, i.e., to movement away from the area centralis. Thus, for these cells direction preference depends on the location of their receptive fields within the visual field.

Velocity preference and binocular interaction in these neurons is also globally organized: Velocity preference increases with eccentricity, binocular synergism is strongest in the center of the visual field. Cluster analysis of recording tracks with respect to "radial" and "circular" cell categories reveals a grouping of cells with like properties in the lateral suprasylvian cortex. These new categories are formed by combining "centrifugal" and "centripetal" cells on the one hand and cells with direction preferences orthogonal to these on the other.

The radial or centrifugal organization of direction preferences in conjunction with the global arrangement of velocity preference and binocular interaction suggests that PMLS and PLLS are involved in the processing of expanding visual flow fields of motion. Such flow fields are commonly encountered when a visual object moves towards an observer or during forward locomotion.

Nervous activity caused by visual stimulation travels along various pathways to a large number of visual cortical areas. Research over the last 30 years has indicated that the neural re-

\footnotetext{
Received Mar. 24, 1986; revised Oct. 20, 1986; accepted Oct. 24, 1986.

We wish to thank Sabine Hahn and Volker Staiger for excellent technical assistance and Shirley Würth for editing the manuscript. Valuable comments on the manuscript were nade by Peter Clarke, Hans-Jürgen Dahmen, Karl Götz, Werner Kriechbaum, Christian Munz, Giacomo Rizzolatti, and Jochen Zeil.

Correspondence should be addressed to Josef P. Rauschecker, Max Planck Institut für Biologische Kybernetik, Spemannstrasse 38, 7400 Tübingen, FRG.

a Present address: Department of Psychology, University of Montreal, Montreal, Quebec, Canada

b Present address: Department of Psychology, Queen's University, Kingston, Ontario, Canada.
}

Copyright (C) 1987 Society for Neuroscience $0270-6474 / 87 / 040943-16 \$ 02.00 / 0$ sponse properties in these areas are well suited to extract specific kinds of visual information (Zeki, 1978; Woolsey, 1981; Van Essen and Maunsell, 1983). Thus, the primary emphasis in different areas may be on the processing of retinal disparity, motion, color, spatial, or other information (Barlow et al., 1967; Hubel and Wiesel, 1977; Zeki, 1980; Newsome et al., 1985).

The main ascending avenue in the visual system of the cat is the geniculostriate pathway, along which information is channeled to the visual cortical areas in the occipital complex. This pathway is interconnected in a number of ways to another main stream, the retinotectothalamic pathway to visual areas in the suprasylvian sulcus, which were first described by Clare and Bishop in 1954 (Hubel and Wiesel, 1969; Gilbert and Kclly, 1975; Spear and Baumann, 1975, 1979; Camarda and Rizzolatti, 1976). This latter pathway has recently gained increasing attention.

A physiological investigation of the extrageniculostriate pathway is made especially attractive at present by the wealth of new anatomical knowledge, which indicates how information is relayed from the retina via the superior colliculus (SC) and the lateral posterior nucleus (LP) in the thalamus to areas PMLS and PLLS in the lateral suprasylvian (LS) sulcus (Maciewicz, 1974; Berman and Jones, 1977; Updyke, 1977, 1981; Berson and Graybiel, 1978; Symonds et al., 1981; Raczkowski and Rosenquist, 1983). There also exists a more direct path from the retina to the medial interlaminar nucleus (MIN) and the C-layers of the lateral geniculate nucleus (LGN) in the thalamus and from there to the LS areas (Rosenquist et al., 1974, 1975; Gilbert and Kelly, 1975; LeVay and Gilbert, 1976; Berman and Jones, 1977; Leventhal et al., 1980).

Receptive field (RF) properties in the LS areas are determined by a combination of inputs from retinothalamic, tectothalamic, and corticocortical pathways. One of the main RF characteristics of cells in PMLS is their pronounced binocularity (Spear and Baumann, 1975; Camarda and Rizzolatti, 1976; Guedes et al., 1983). A second well-established characteristic is directional selectivity, which is found in up to $90 \%$ of the cells (Spear and Baumann, 1975, 1979; Camarda and Rizzolatti, 1976). In general, cells in LS are also distinguished by their relatively large RF sizes, even in the center of the visual field, and the broad range of stimulus velocities to which they respond. The majority of cells will respond optimally to nonoriented stimuli such as light or dark spots of a specific size (Spear and Baumann, 1975; Camarda and Rizzolatti, 1976).

A majority of direction-selective cells in PMLS have also been found to have a more complex RF organization, best described by a double-opponent process (von Grünau and Frost, 1983). Compared with movement of a spot alone anti-phase movement of the optimal spot on a large moving random-noise background 
field often results in an increase of the response, and in-phase movement almost always produces a significant response reduction. This indicated that PMLS cells may be involved in figure-ground discrimination, leading to the detection of objects moving relative to the environment or in discriminating selfinduced motion from object motion (Frost, 1985).

Organisms would encounter this stimulus situation when moving through their environment in the presence of stationary or moving targets (Gibson, 1950, 1966). The organism's locomotion will create visual flow fields, which carry information about the direction of locomotion, the speed of locomotion, and variables related to head position and posture (Richards, 1975; Regan and Beverley, 1982; Nakayama, 1985). In the present study, we have first attempted to examine the direction selectivity of LS neurons specifically with respect to their possible involvement in the analysis of flow field information and tried to identify different subpopulations of neurons in terms of visual response properties.

Several further predictions can be made as to how other response properties of LS neurons should be organized globally in order to fit the purpose of a visual subsystem for the analysis of centrifugal flow fields. One prediction is that the selectivity for stimulus velocity should be broad in general, accounting for different speeds of motion, but that it should vary with eccentricity. Another requirement is a strong binocular interaction to support synergism of ocular movements, so as to maintain fixation on the approaching object.

While some of these response properties have been described locally (Spear and Baumann, 1975; Camarda and Rizzolatti, 1976), their global organization across the visual field has not been examined.

Several brief accounts of parts of this research have been published in abstract form (Rauschecker et al., 1983; von Grünau et al., 1983; Poulin et al., 1984; Rauschecker et al., 1984).

\section{Materials and Methods}

Data were collected from 12 electrode penetrations in 6 cats. All animals were adults and had been raised in a normal environment.

Single-unit recording. Standard techniques for extracellular singleunit recording were applied. The animal was initially anesthetized with ketamine hydrochloride (Ketanest, $25 \mathrm{mg} / \mathrm{kg}$, i.m.) and xylazine (Rompun, $2 \mathrm{mg} / \mathrm{kg}, \mathrm{i} . \mathrm{m}$.) after premedication with atropine sulfate $(0.05 \mathrm{mg}$, s.c.). Anesthesia was maintained throughout the experiment by adding halothane (Fluothane) to the usual $70 / 30$ mixture of $\mathrm{N}_{2} \mathrm{O} / \mathrm{O}_{2}$ respiration gases. The concentration of halothane was set to $1 \%$ initially and was then reduced stepwise to $0.4 \%$. During the whole experiment the depth of anesthesia was controlled by monitoring the EEG and electrocardiogram. No responses were produced to noxious stimuli with a halothane concentration of $0.4 \%$. In preparation for artificial respiration, a tracheotomy was performed, and the animal was then fixed in a stereotaxic headholder. The skull was opened over the suprasylvian sulcus (L10L16, A0-A8). After surgery was completed the animal was paralyzed with gallamine triethiodide (Flaxedil, $20 \mathrm{mg} / \mathrm{kg} / \mathrm{hr}$ ) and artificially respirated as noted above. Body temperature was kept at $38^{\circ} \mathrm{C}$ with an automatically controlled heating pad; end-tidal $\mathrm{CO}_{2}$ was measured with a Beckman monitor and kept at 3.8\%. The animal's eyes were protected by contact lenses containing $3 \mathrm{~mm}$ pupils, treated with neosynephrine (to retract the nictitating membranes), and 1\% ophthalmic atropine solution (to paralyze the ciliary and sphincter muscles), and focused on a tangent screen $171 \mathrm{~cm}$ away.

Extracellular recordings from single units in PMLS and PLLS between stereotaxic coordinates $\mathrm{A} 2$ and $\mathrm{A} 7$ were obtained with double-barrel micropipettes, one chamber of which was filled with $1.5 \mathrm{M} \mathrm{K}$ ' citrate and the other with a $3 \%$ solution of HRP in $0.2 \mathrm{M} \mathrm{KCl}$ and $0.05 \mathrm{M}$ Tris buffer ( $\mathrm{pH} 7.6)$, in order to mark the electrode tracks. Data were obtained only from single-unit recordings; typically, cells were isolated every 50 $100 \mu \mathrm{m}$. With our micropipettes (impedance, $10 \mathrm{M} \Omega$ at $1 \mathrm{kHz}$ ), it was possible to make unequivocal identification of successive recordings as being derived from the same or different neurons. The electrode was pointed medially and deviated from the vertical by an angle of $30^{\circ}-40^{\circ}$, thus following one bank of the sulcus from top to bottom. Some penetrations traversed the suprasylvian sulcus and contained recordings from both banks. The right hemisphere was used in all but 1 animal, so that most cells had RFs in the left hemifield (Palmer et al., 1978). Responses were assessed by listening to an audio monitor and by recording triggered spikes with a PDP 11/34, which delivered on-line raster displays and averaged peristimulus-time histograms (PSTHs). The raster displays preserved information about every sweep and therefore provided valuable information about the degree of response variability.

Light stimulation. The positions of retinal landmarks (optic disc and area centralis) of both eyes were projected onto the tangent screen with a Zeiss fundus camera. For specific testing of binocular interactions, both areae centrales could be made to overlap using Risley prisms. Visual stimuli consistcd of spots and bars of various sizes with a luminance of $2.5 \mathrm{~cd} / \mathrm{m}^{2}$, that were projected onto a tangent screen of 0.1 $\mathrm{cd} / \mathrm{m}^{2}$ luminance. The position and size of the receptive field were determined for each isolated cell and marked on the screen. Among other parameters, optimal spot size, optimal velocity, velocity tuning, ocular dominance, directional tuning, and response quality were determined.

Special attention was given to the assessment of direction selectivity for a moving stimulus: analysis was usually started with a hand-held projector and in most cases, especially unclear ones, followed by quantitative measurements with a computer-controlled optical bench system. PSTHs were produced for at least 8 , and sometimes 16 , directions of movement from 10 or more runs in each direction. Runs in one direction were always interleaved with runs in the opposite direction. Directions (in dcg) werc defincd as follows: $0^{\circ}$, horizontal to the right; $90^{\circ}$, vertical up; $180^{\circ}$, horizontal to the left; $270^{\circ}$, vertical down; etc. Categories were separated by $22.5^{\circ}$. Preferred direction was designated as the direction of movement that resulted in the maximal number of spikes per sweep. Directional tuning borders were determined from those 2 directions of stimulus movement that just failed to elicit an increase in discharge rate. Cells for which such tuning borders could be determined, independent of their tuning width, were called "directionally selective" (DS). If a cell responded to all directions but showed a preferred direction, it was termed "directionally biased" (DB). The combination of handplotting and quantitative analysis seems a fair compromise between purely quantitative data collection and the need for representative cell samples (see Rauschecker and Singer, 1981).

Histology. In every experiment, the paths of the recording electrodes were reconstructed histologically. The penetrations in LS were marked at 2 or more places by iontophoretic $(10 \mu \mathrm{A})$ injection of HRP through the recording micropipette. This resulted in HRP deposits of 50-100 $\mu \mathrm{m}$ core diameter. At the end of the experiment, the animals were perfused transcardially with Ringer's solution $(0.9 \% \mathrm{NaCl})$ followed by Karnovsky fixative $(0.5 \%$ paraformaldehyde, $2 \%$ glutaraldehyde in 0.1 M phosphate buffer; Karnovsky and Roots, 1964). The brains were cut into $50-\mu \mathrm{m}$-thick sections. The sections were stained by the tetramethyl benzidine (TMB) method (Mesulam, 1978), which generates a highcontrast nondiffusible reaction product with HRP that allows reliable localization of the electrode track. All sections were counterstained with a standard neutral red procedure.

\section{Results}

Single-cell activity was recorded from both banks of the suprasylvian sulcus. Seven penetrations were restricted entirely to the medial bank, one to the lateral bank; 4 electrode tracks started in the medial bank, penetrated the suprasylvian sulcus and then traveled through the lateral bank.

\section{Responsiveness}

The majority of cells in both areas $(213 / 253=84 \%)$ responded briskly to light stimulation and showed selectivity for a number of stimulus features. Only in 1 penetration (PLS 5/1) was a consecutive series of unresponsive units found. Since this was the initial portion of the track and cells responded briskly in deeper parts, we doubt whether these neurons really belonged 

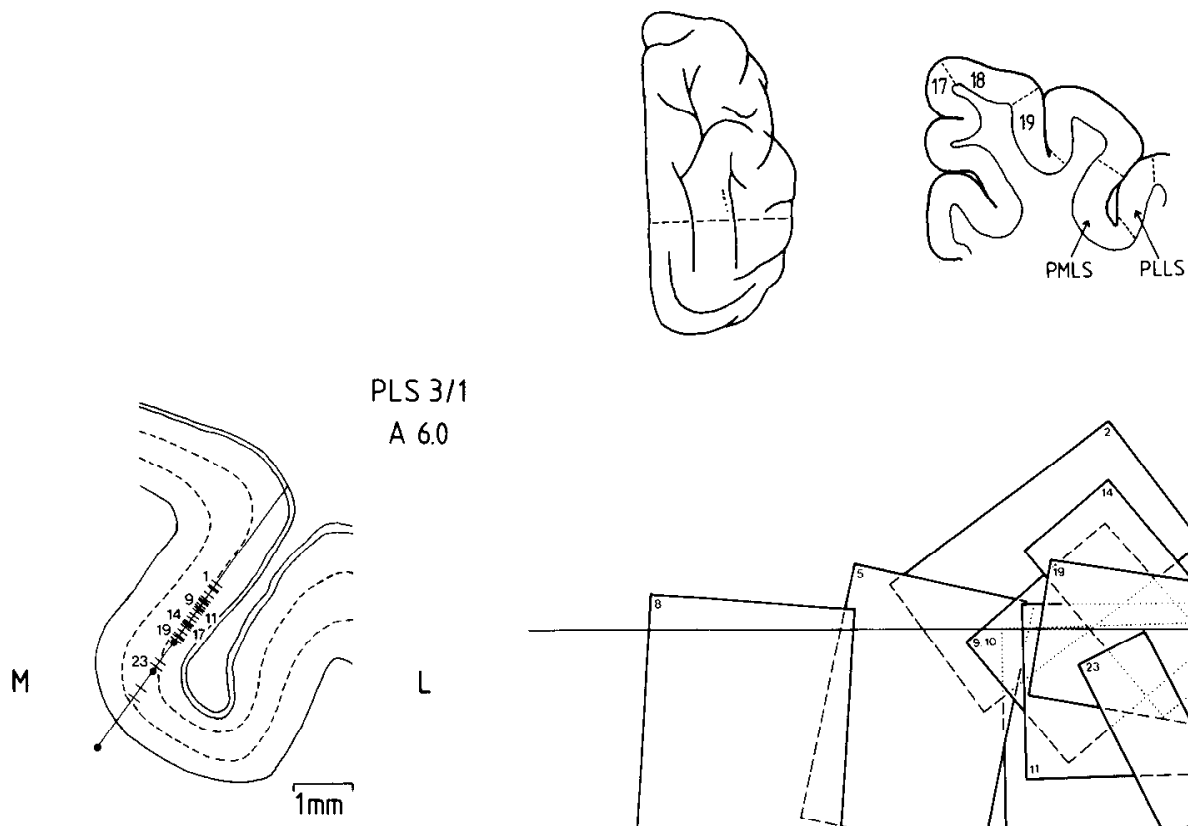

PLS $3 / 1$

A 6.0

L
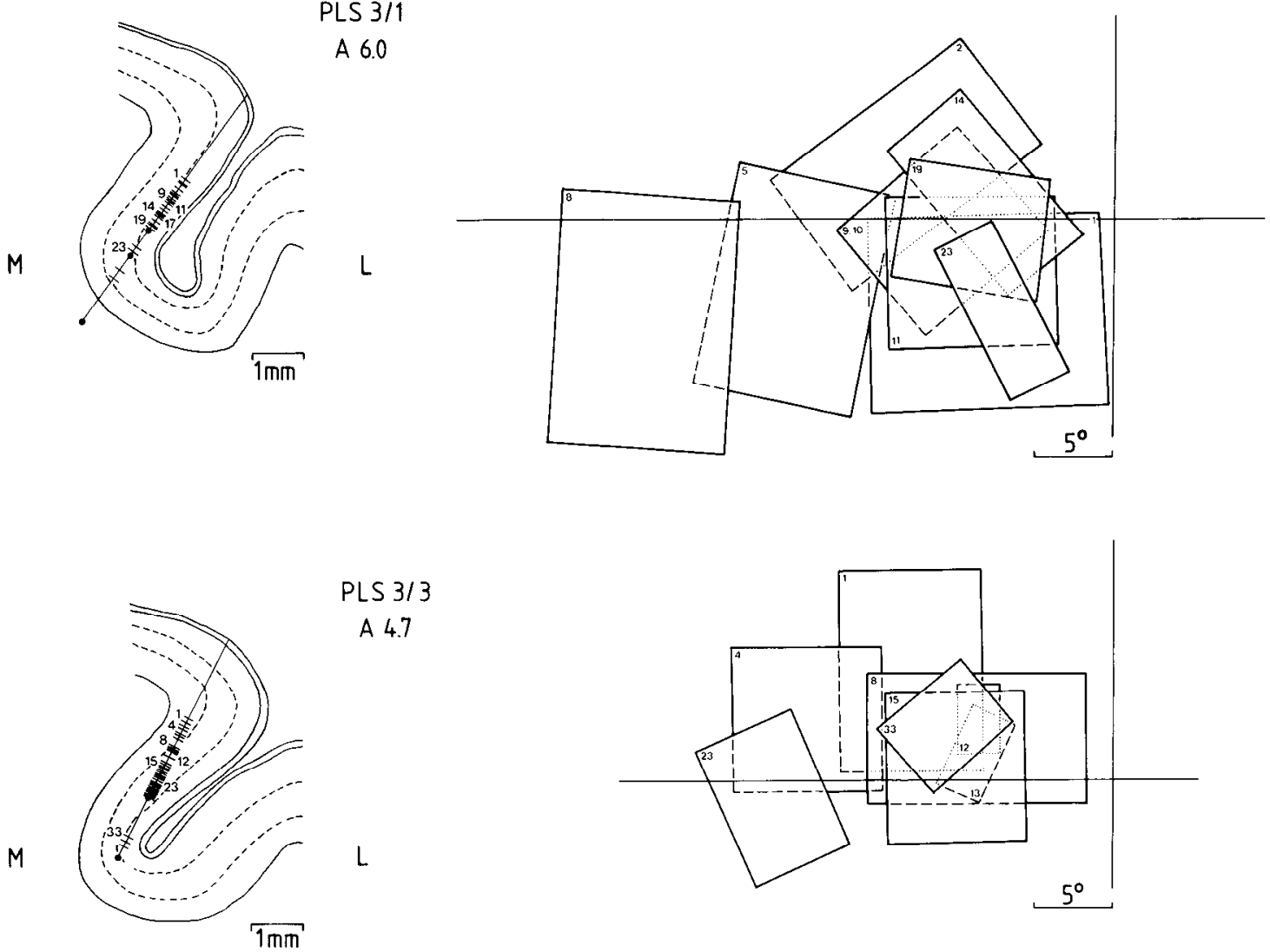

PLS 3/3

A 4.7

L

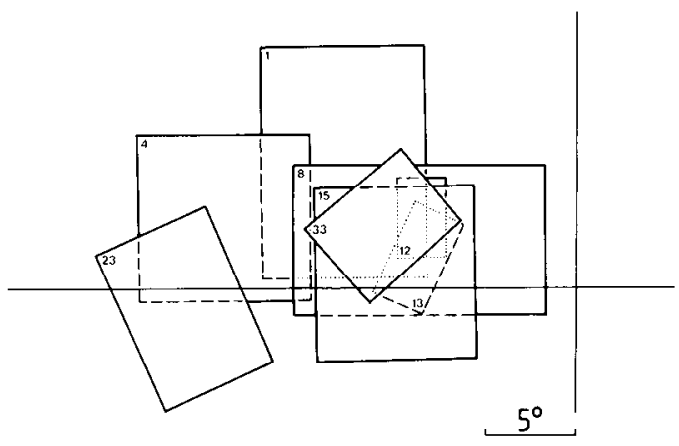

PLS $5 / 1$

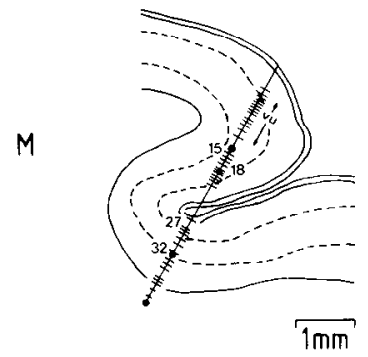

A 4.0

L

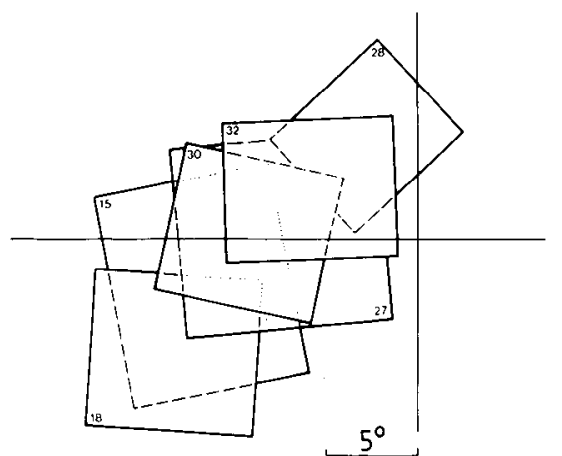

Figure 1. Track reconstructions of 3 electrode penetrations in LS of the right cerebral hemisphere. RFs are approximated by rectangles in the conventional way (Barlow et al., 1967; Hubel and Wiesel, 1969). Top, Two electrode tracks entirely restricted to the medial bank (M) of the suprasylvian sulcus (PMLS). Bottom, Example of an electrode track starting in the medial bank and traversing the suprasylvian sulcus into the lateral bank $(L) ; v u$ : visually unresponsive units. Small HRP deposits are shown as dark spots. The approximate borders of layer 4 , as apparent from Nissl-stained sections, are drawn as dashed lines. In the RF plots, dashed lines indicate overlap, dotted lines indicate multiple overlap (i.e., parts of that RF plot being covered by more than 1 subsequent RF). 
to PMLS. If they are excluded from analysis, the total proportion of briskly responsive units reaches $89 \%$. Thus, in our hands, there was no major tendency for cells in LS to be more sluggish or less responsive to light stimulation than neurons in striate cortex.

\section{Topography and scatter}

Our electrode penetrations were situated along an anteroposterior extent of about $5 \mathrm{~mm}$ in the suprasylvian sulcus between Horsley-Clarke coordinates $\mathrm{A} 2$ and $\mathrm{A} 7$, the majority being between A4 and A6 (Reinoso-Suarez, 1961). Penetration angles varied between $30^{\circ}$ and $40^{\circ}$ from the vertical. Figure 1 shows some examples of track reconstructions.

\section{Visuotopic organization}

According to Palmer et al. (1978), the RFs corresponding to stereotaxic coordinates A4-6 should lie roughly along the horizontal meridian and in the upper quadrant of the contralateral visual field both for PMLS and PLLS. Moving the electrode down into the fundus of the suprasylvian sulcus should cause the fields to move inward towards the vertical meridian (Hubel and Wiesel, 1969; Spear and Baumann, 1975; Palmer et al., 1978). By and large, both trends were observed. However, as was also notcd in some of these previous studies (e.g., Hubel and Wiesel, 1969), the inward movement of the RFs was not always continuous but often occurred in jumps. Also, at our more posterior penetrations $(A<5)$ down the medial bank, the RFs did not reach the vertical meridian at the fundus. On the other hand, at anterior positions of A5.6 or more, the vertical meridian representation (with an overlap into the ipsilateral hemifield) was already reached half way down the medial bank. This leads us to the conclusion that the representation of the vertical meridian does not strictly follow the fundus of the suprasylvian sulcus. Rather, it seems to run obliquely, starting on the medial bank at more anterior positions and lying on the lateral bank more posteriorly. The crossover point lies at around A5.

Correspondingly, lines of constant azimuth seem to run obliquely on the medial bank. Our own data and those of previous studies (Hubel and Wiesel, 1969; Spear and Baumann, 1975) are also compatible with a representation of isoelevations much simpler than that suggested by Palmer et al. (1978): in our scheme isoelevations run perpendicularly to the isoazimuths. Thus, in a frontoparallel electrode penetration traveling down the medial bank, RFs shift from lower to higher elevations and from peripheral parts of the visual field toward the vertical meridian. A good example of this trend is track PLS 5/1 (Fig. 1).

\section{Scatter in tangential penetrations}

Two electrode tracks were successful in tangentially penetrating to the cortical surface, down the medial bank of the suprasylvian sulcus. They were thus largely confined to 1 cortical layer (Fig. 1). Track PLS $3 / 1$ remained in layer 3 for a distance of $1-1.5$ $\mathrm{mm}$, while track PLS 3/3 ran through layer 4 for about the same distance. A comparison of the cells in these penetrations gave some hints as to the RF organization of PMLS by afferent, in contrast to intracortical, connectivity.

With regard to RF scatter, it was surprising to see how little the fields moved in the visual field, when the electrode moved over more than $1 \mathrm{~mm}$ in layer 4 (track PLS 3/3). All RFs between cells 12 and 29 were practically at the same place with an eccentricity of $8^{\circ}$. Even from unit 1 (in layer 5) to unit 35 (in layer 3 ), which span a distance in cortex of $3 \mathrm{~mm}$, there was considerable overlap in their RFs. From these observations a lower estimate for the magnification factor of $1-2 \mathrm{~mm} / \mathrm{deg}$ at $5^{\circ}-10^{\circ}$ eccentricity can be given, which is comparable to the values found for the same eccentricity in cat and monkey striate cortex (Hubel and Wiesel, 1974; Albus, 1975; Tusa et al., 1978).

\section{RF size, shape, and summation properties}

Size distribution

The size of the RFs varied over more than $2 \log$ units, from about $10 \mathrm{deg}^{2}$ to about $1000 \mathrm{deg}^{2}$. The majority of the fields had sizes between 20 and $200 \mathrm{deg}^{2}$. A separate, smaller, group was formed by neurons with RF sizes between 9 and $15 \mathrm{deg}^{2}$. They were found exclusively in layer 4 of both PMLS and PLLS. The modal value of the total population was $65 \mathrm{deg}^{2}$; the median, $75 \mathrm{deg}^{2}$.

There was no significant difference between PMLS and PLLS with regard to RF size in our sample. The fact that the distribution was somewhat narrower for PLLS cells is probably due to the smaller range of eccentricities at which RFs were registered. In both PMLS and PLLS RF size depended on eccentricity; however, this was not as pronounced as, for example, in area 17 (Hubel and Wiesel, 1974). The main effect seemed to be an increasing scatter of RF sizes with increasing eccentricity. Often, RFs of widely differing size were centered at the same point in visual space.

\section{RF shape}

Most cells had elliptic or circular RFs, which are approximated by rectangles in all our plots (see Barlow et al., 1967; Hubel and Wiesel, 1969, 1974). Since most cells in LS are direction selective (Spear and Baumann, 1975; see also below), a preferred axis of movement can be defined. Contrary to what is found for most simple cells in area 17 , neurons in LS very often possess RFs whose greatest extent is along this preferred axis, rather than orthogonal to it.

\section{Spatial summation}

Complex oscillatory responses with more than 1 peak were often obtained when spots or bars of light were flashed on the RFs of LS cells. By varying the size of the light stimulus it was found that these peaks changed their amplitude quite independently (Fig. 2, $A, B$ ). This suggests that different inputs are responsible for the generation of the peaks.

Increasing the area of light stimulus in many cells led to a clear effect of spatial summation until, beyond a certain size, a reduction of the response amplitude was observed. This clearly indicates the existence of an inhibitory surround in many LS cells, as previously recognized by Rizzolatti and Camarda (1975, 1977). An example of such a cell is shown in Figure $2 C$. In this cell a response reduction was observed both with a narrowing of stimulus width (i.e., decrease of spatial summation) and with an extension of stimulus length (i.e., increase of surround inhibition). The most dramatic reduction, as shown in Figure 2, was reached by a combination of both. Therefore, both factors, spatial summation within the RF and surround inhibition, may 
A

PLS $604(10 / 300 / 20)$
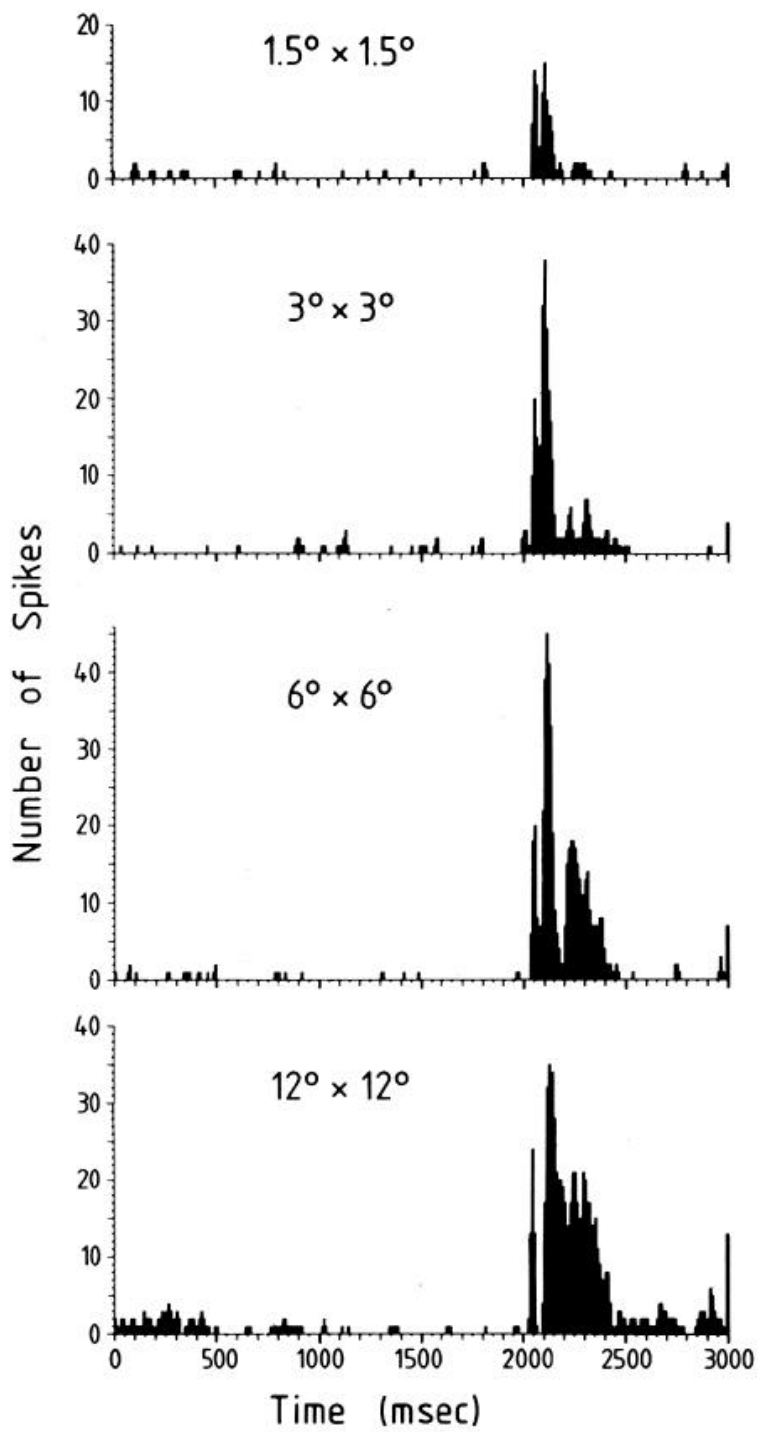

B

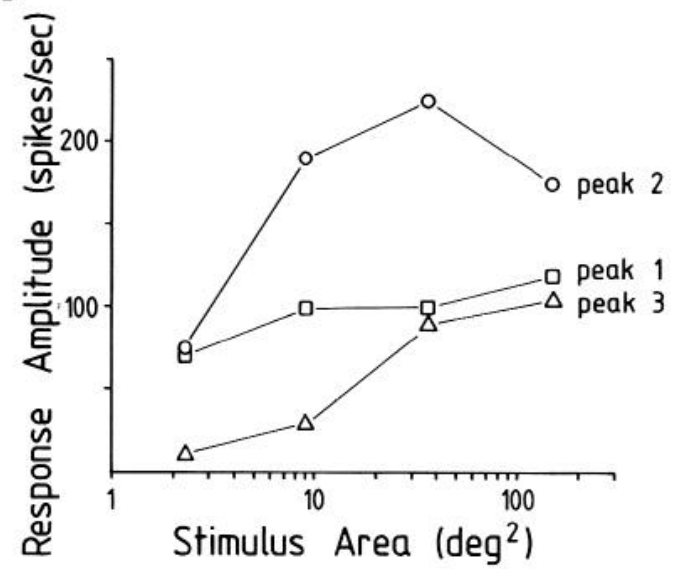

C
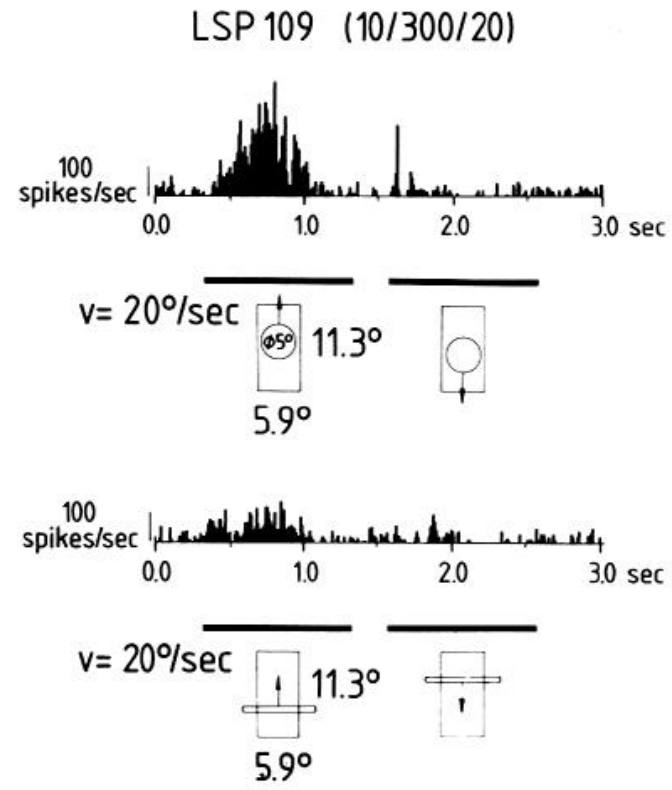

Figure 2. Spatial summation properties of LS neurons. $A$ and $B$, Example of a neuron in PMLS with an oscillatory response to light stimuli of different sizes flashed on the RF. A, Peristimulus-time histograms (PSTH). Numbers in brackets give bin width (in msec), number of bins per epoch, and number of epochs, respectively. Dimensions of the rectangular stimuli are given for each PSTH. $B$, Diagrammatic representation of amplitudes of the peak responses. Peaks are numbered consecutively from left to right. $C$, PSTHs to a light stimulus moving across the RF in the preferred direction and back. Upper histogram, Response to a spot of light with a diameter corresponding approximately to the width of the RF; lower histogram, response to bar stimulus narrower than the diameter of the spot stimulus but longer than the RF borders. Comparison of the 2 histograms demonstrates the combined influence of spatial summation and surround inhibition, 2 factors that may both contribute to the apparent "size selectivity" of LS cells.

contribute to the apparent size selectivity of RFs in the LS areas (Spear and Baumann, 1975).

\section{Binocular interactions}

\section{Ocular dominance}

We determined ocular dominance (OD) quantitatively in 173 neurons of the posterior lateral suprasylvian cortex. One hundred and twenty-nine of these cells were recorded from PMLS, 44 from PLLS. In both PMLS and PLLS the vast majority of the cells were binocular (Fig. $3 A$ ). Units equally activated from either eye (OD class 3 in our scheme) comprised $61 \%$ of our sample (59\% in PMLS and 66\% in PLLS). Only 4.6\% (8/173) of the cells were truly monocular (OD classes 1 and 5); all of these had RF centers more than $10^{\circ}$ away from the area centralis. None of the cells was driven monocularly by the ipsilateral eye.

A comparison of PMLS and PLLS revealed an interesting trend towards even less monocularity and towards a more equal balance between contra- and ipsilateral eye in PLLS (Fig. $3 A$ ): In PMLS 4 times as many cells were dominated by the contrathan the ipsilateral eye (OD 2 vs OD 4), whereas in PLLS only 2-3 times as many cells were dominated by the contralateral eye. The difference between the 2 distributions was significant at the 0.01 level (2-tailed $\chi^{2}$ test, $\left.2 \times 3\right)$. 
A

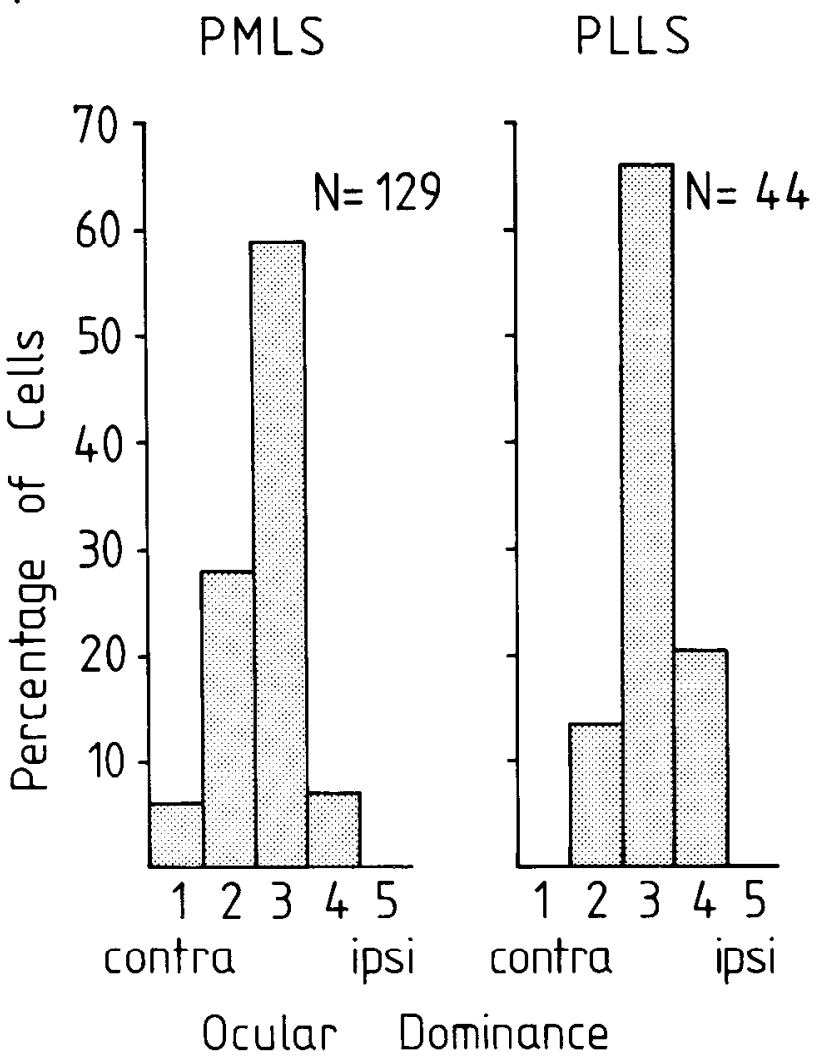

B

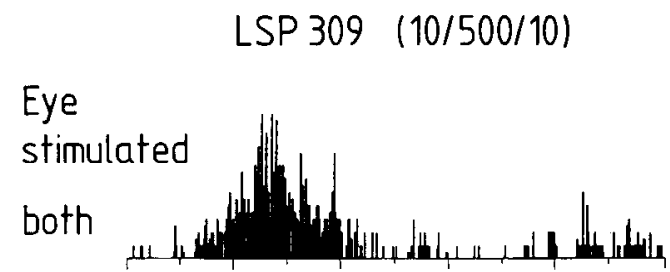

contra
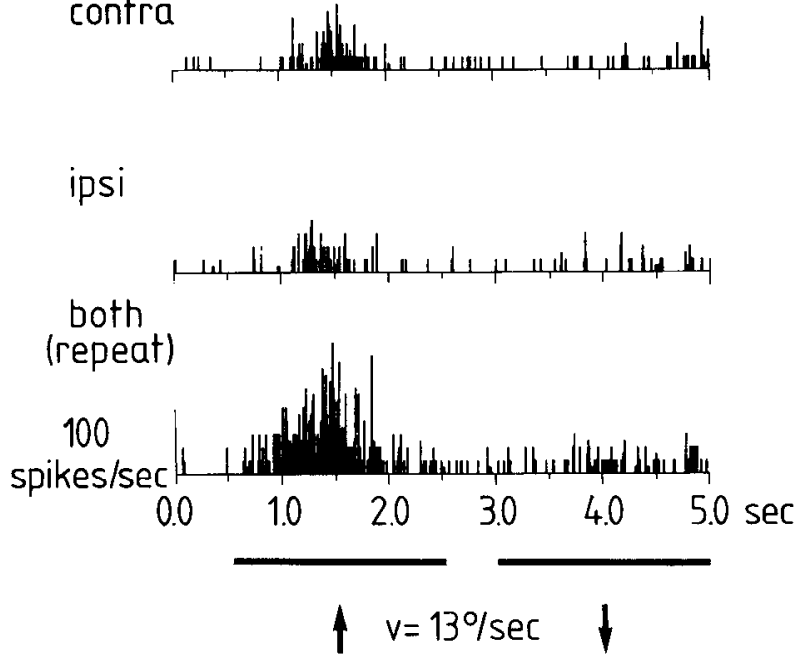

Figure 3. Binocularity of LS neurons. A, Ocular dominance distributions of cells in 2 visual areas of the lateral suprasylvian cortex (PMLS and PLLS). The 5 ocular dominance classes are defined as follows: 1 , exclusively influenced from the contralateral eye; 2 , predominantly influenced from the contralateral eye; 3 , about equally influenced from either eye; 4 , predominantly influenced from the ipsilateral eye; 5 , exclusively influenced from the ipsilateral eye. Cells that could be driven only through 1 eye when stimulated monocularly but showed binocular facilitation were counted in classes 2 and 4, respectively, according to the above definition. AND units, i.e., those responding only to simultaneous stimulation of both eyes, were counted in class 3. B, Binocular facilitation in a neuron from PMLS. The cell had a large RF $\left(34^{\circ} \times 21^{\circ}\right)$ extending along the horizontal meridian from $2^{\circ}$ eccentricity $36^{\circ}$ out into the visual field periphery. Direction preference was upwards. The stimulus consisted of a light spot with a diameter of $1.7^{\circ}$ moving up and down with a velocity of $13 \% \mathrm{sec}$ and an amplitude of $26^{\circ}$. From top to bottom the histograms show the responses of the cell to stimulation through both eyes together, through the contralateral eye alone, the ipsilateral eye alone, and a control repeat trial with stimulation through both eyes again. The parameters of the PSTHs (bin width, number of bins, and number of summed trials) were the same in all cases and are given at the top in parentheses.

\section{Binocular facilitation}

Most of the cells, whose OD was determined by stimulating either eye separately, were also tested for binocular interactions by stimulating both eyes simultaneously. Eye alignment was within $2^{\circ}$ in all cats. Binocular interactions were defined as follows: Binocular inhibition occurred when the cell's response to simultaneous binocular stimulation was smaller than the response to monocular stimulation of the dominant eye. Binocular summation was present when the cell's response to binocular stimulation was larger than that for the dominant eye. When the binocular response was greater than the sum of the 2 monocular responses, the cell was said to show binocular facilitation.

Binocular inhibition was seen in only $3 \%$ of the units in our sample. However, more than half of the cells tested $(78 / 135=$ $58 \%$ ) showed binocular summation or facilitation. In 1 cat the proportion of units with binocular summation or facilitation was as high as $78 \%$. There was no significant difference between PMLS and PLLS for this property. A typical example of a cell from PMLS with binocular facilitation is shown in Figure $3 B$. The response increase by binocular facilitation could exceed
$400 \%$ and occurred equally often among cells with balanced (OD 3) and unbalanced input (OD 2 and 4).

Extreme cases of binocular facilitation were seen occasionally, in which the cells would not respond at all to stimulation of

Table 1. Directional tuning of neurons in LS

\begin{tabular}{|c|c|c|c|c|c|c|}
\hline \multirow[b]{2}{*}{ Tuning } & \multirow[b]{2}{*}{$\begin{array}{l}\text { Width } \\
\text { (+ deg) }\end{array}$} & \multirow[b]{2}{*}{$\begin{array}{l}\text { PMLS } \\
n\end{array}$} & \multirow[b]{2}{*}{$\begin{array}{l}\text { PLLS } \\
n\end{array}$} & \multicolumn{3}{|l|}{ LS } \\
\hline & & & & $n$ & $\%$ & $\begin{array}{l}\text { Total } \\
\%\end{array}$ \\
\hline $\mathrm{DS}$ & 22.5 & 10 & 3 & 13 & 10.7 & 50.4 \\
\hline \multirow[t]{2}{*}{ narrow } & 45 & 33 & 15 & 48 & 39.7 & \\
\hline & 67.5 & 12 & 12 & 24 & 19.8 & \\
\hline DS, & 90 & 9 & 6 & 15 & 12.4 & 33.9 \\
\hline broad & 112.5 & 2 & 0 & 2 & 1.7 & \\
\hline DB & 180 & 12 & 7 & 19 & 15.7 & 15.7 \\
\hline Total & & 78 & 43 & 121 & 100.0 & 100.0 \\
\hline
\end{tabular}

DS: direction selective; DB: direction biased. Cells without a preferred direction not included. 

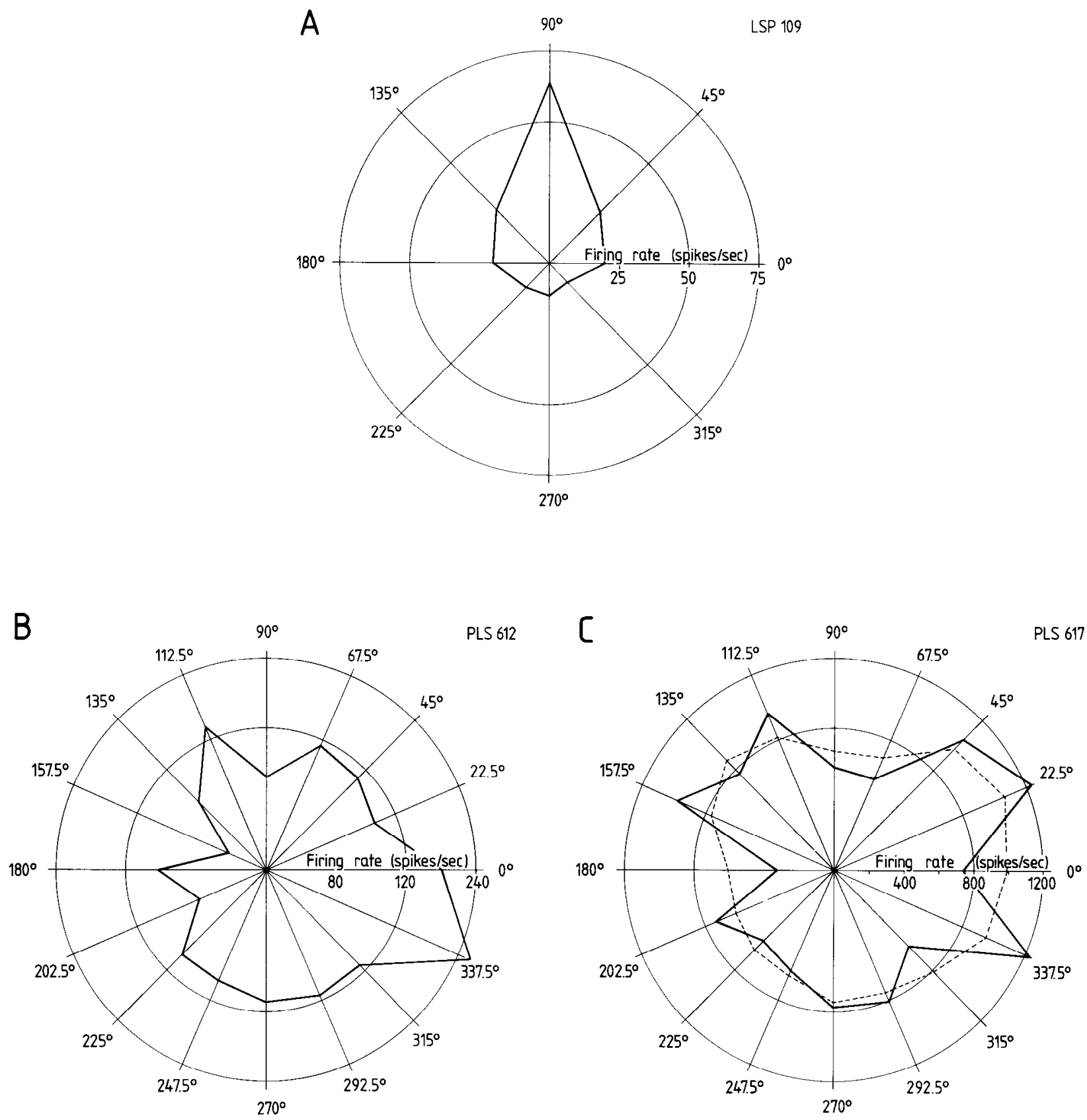

Figure 4. Directional selectivity of cells in LS. $A-C$, Examples of directional tuning curves from 3 neurons with different degrees of selectivity (see Table 1 and text). The cell in $A$ displays "narrow" tuning $\left( \pm 45^{\circ}\right)$ and the cell in $B$ "broad" tuning ( $\pm 135^{\circ}$ ); both would be termed "direction selective" (DS). The cell in $C$ is "directionally biased" (DB; see Materials and Methods). The preferred direction in $C$ was taken from a smoothed version of the tuning curve (dashed line), since the raster displays indicated that the multiple peaks were only caused by response variability.

either eye alone but responded vigorously to congruous stimulation of both eyes (AND units). Also in a number of cases a response was detectable only from 1 eye when monocularly tested, but this response was greatly enhanced with binocular testing. We decided to classify the former cells as belonging to ocular dominance class 3 and the latter to classes 2 or 4 , since a connection from either eye obviously had to exist to mediate the facilitatory effect.

\section{Direction selectivity}

In 197 cells (136 in PMLS, 61 in PLLS), the response to different directions of a moving light stimulus (usually a spot) was determined (see Fig. $2 C$ and $3 B$ for examples of typical responses recorded as PSTH). For 183 cells $(=93 \%)$ a preferred direction could be found. For 121 of these $(=66 \%)$ the directional tuning was measured quantitatively also with the help of PSTHs and raster displays assembled for at least 8 different directions in a partly interleaved fashion (see Materials and Methods). Only $7 \%$ of the cells in LS (14/197) were not direction selective.

\section{Directional tuning}

The width of directional tuning for our sample of cells from PMLS and PLLS is summarized in Table 1. The tuning widths have been grouped into categories differing by $22.5^{\circ}$, tuning borders corresponding to those 2 directions of a moving stimulus that just failed to elicit an increase in discharge rate. The 


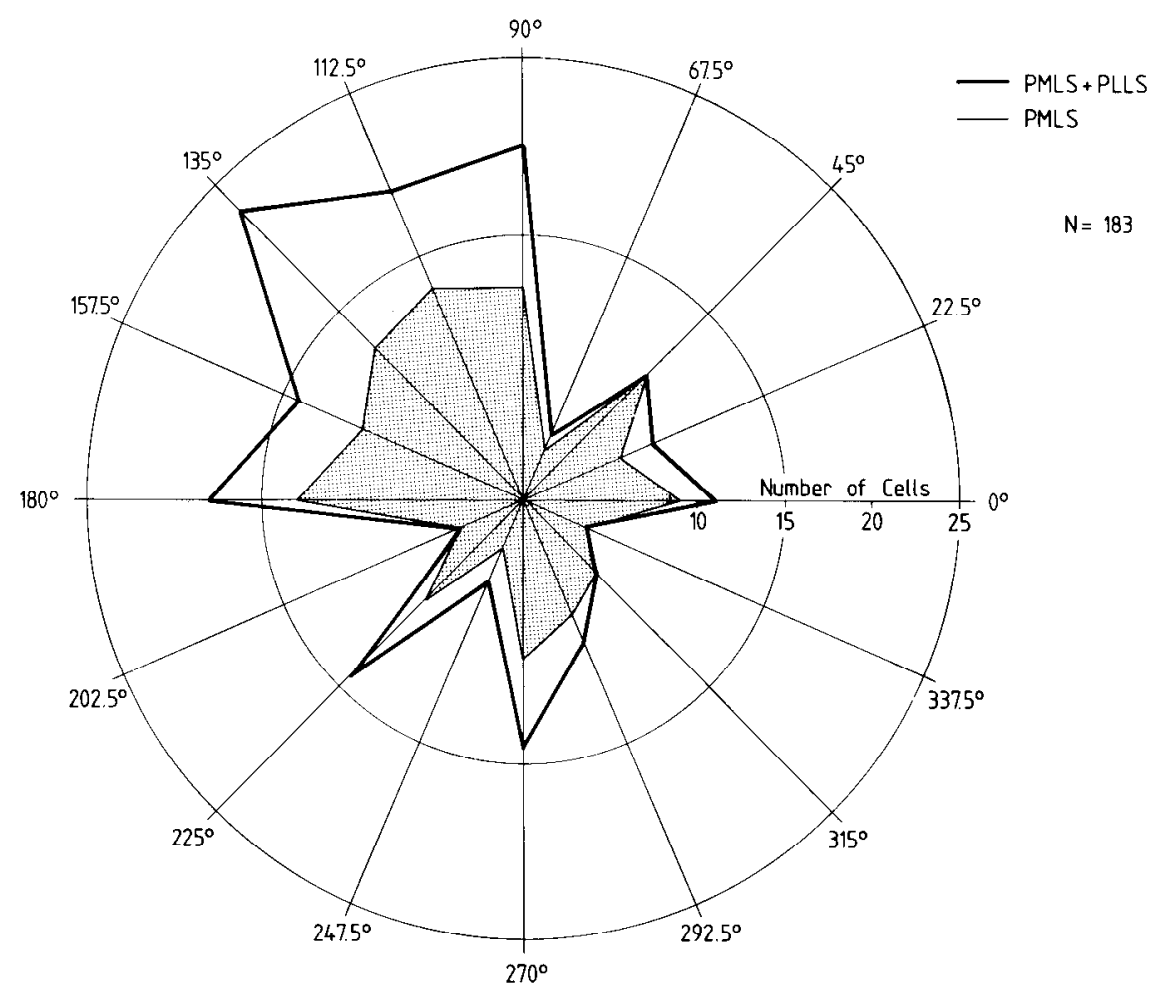

Figure 5. Distribution of direction preferences in lateral suprasylvian cortex (PMLS and PLLS). A, Polar plot shows the number of cells with a certain preferred direction. Movement to the right corresponds to $0^{\circ}$; upward, $90^{\circ}$. leftward, $180^{\circ}$; and downward, $270^{\circ}$. The shaded part of the polar plot shows direction preferences of PMLS cells only. Quantitative analysis was usually done for the 8 main directions $\left(0^{\circ}, 45^{\circ}, 90^{\circ}\right.$, etc.) only, and in some cases was extended to the 8 intermediate directions $\left(22.5^{\circ}, 67.5^{\circ}\right.$, etc. $)$ in a partly interleaved fashion. $B$, Vector fields of preferred directions from 4 experiments. As indicated at the top, filled circles represent the RF centers of cells recorded from PMLS and open circles from PLLS. Circles without an arrow indicate RFCs of cells without a preferred direction.

B

PLS 3

PLS 4

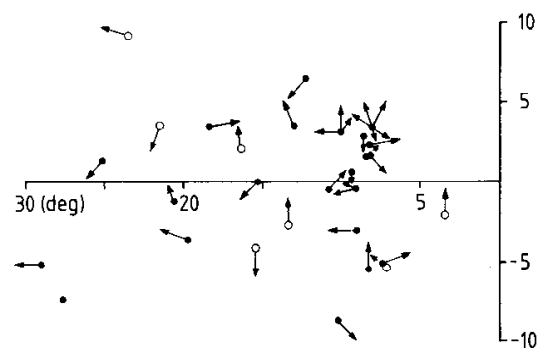
OPLLS

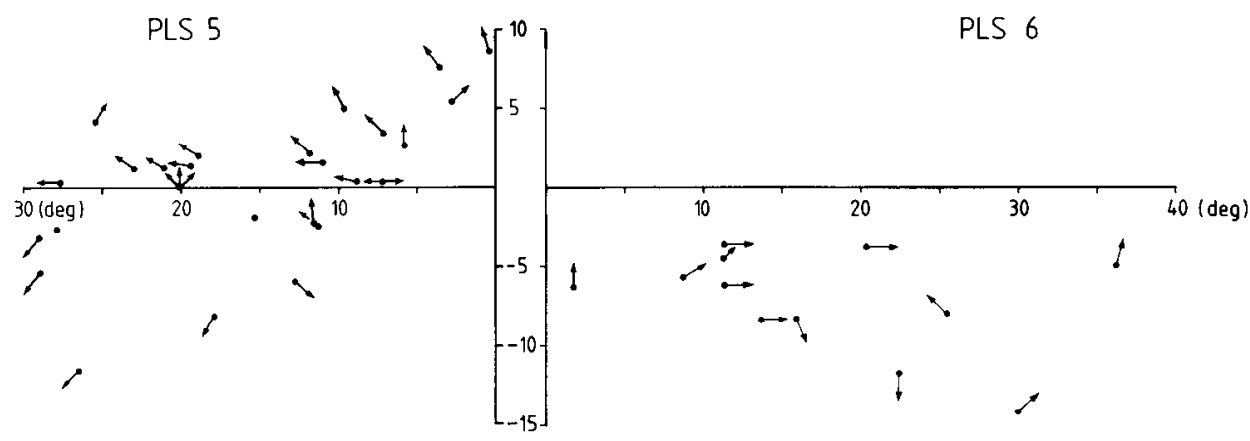

biggest group $(48 / 121=40 \%)$ is formed by cells responding within $\pm 45^{\circ}$ of the preferred direction. One can further classify the cells into different categories (narrow tuning, broad tuning, direction biased), as indicated in Table 1 , but it is doubtful whether these represent real classes of neurons and not simply a continuum. Some examples of cells with different directional selectivity are shown in Figure 4. Only in a few cases were bilobed polar plots of directional tuning seen, which did not seem to be caused by response variability (Zumbroich and Blakemore, 1985).

\section{Direction preference}

A preferred direction could be determined in $93 \%$ of the units $(183 / 197)$. Figure $5 A$ shows a polar plot for direction preference 


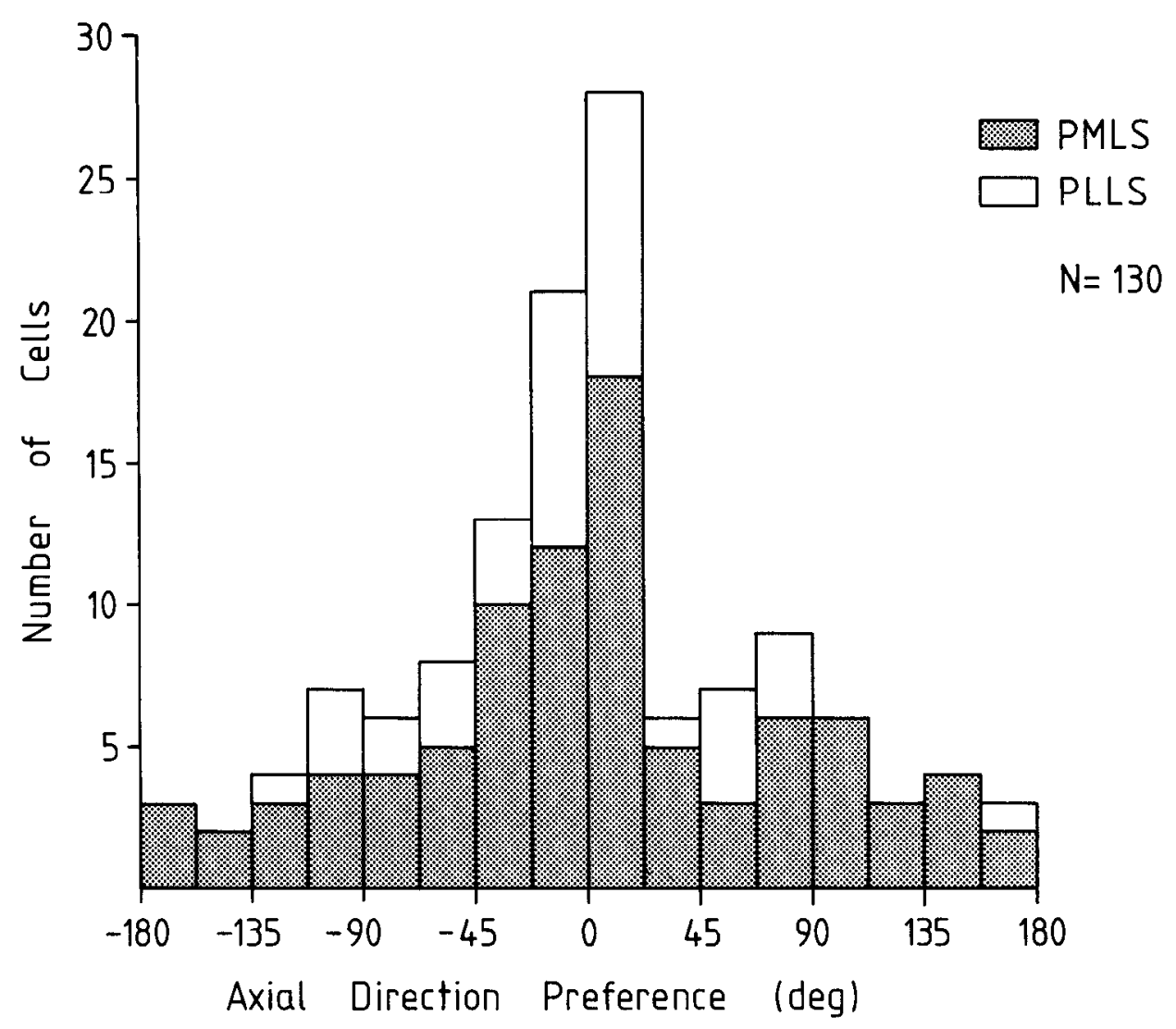

Figure 6. Distribution of axial direction preferences. Axial direction preference is the difference between a cell's preferred direction and the vector pointing away from the area centralis originating in the cell's RFC. in all LS cells from our sample. A preference of $90^{\circ}$ and $270^{\circ}$ refers to upward and downward movement; $0^{\circ}$ and $180^{\circ}$ are assigned to movement into the ipsi- and contralateral periphery of the visual field. Since most RFs had their centers in the contralateral field, $0^{\circ}$ will usually be referred to as movement towards the midline or nasal, $180^{\circ}$ as movement away from the midline or temporal.

Two points are immediately obvious from the polar plot in Figure $5 \mathrm{~A}$ : The majority of cells prefer movement away from the midline (left half of the plot) rather than towards it. Even more specifically, more cells in our sample seem to have a preference for stimuli moving into the upper contralateral visual field quadrant $\left(90^{\circ}-180^{\circ}\right)$. This is the case for our samples from both PMLS and PLLS.

Direction preference was usually the same for both eyes. There was also no hint that preferred direction varied within the receptive field, although this was not tested systematically. This fact (that within the often very large fields a constantly directionselective response could be evoked with small moving spots of light) would suggest that LS fields are generated from a convergence of smaller subunits with the same direction preference. We have not tested whether and how directional selectivity is influenced by such parameters as the size, velocity, and/or contrast of the moving stimulus.

\section{Global organization of direction preference}

Direction preference as a function of $R F$ location

The unexpected bias in the distribution of direction preferences for movement up and away from the midline led us to suspect that there may be a correlation between this bias and the fact that most cells in our sample had RFs in the upper contralateral quadrant. We have therefore evaluated the direction preference of individual cells as a function of the location of their RF center (RFC) in the visual field. This was done in 2 ways: In Figure $5 B$ RFCs are replotted in the usual coordinates (azimuth and elevation) with a small arrow indicating the direction preference of the unit. Usually the geometric center of the RF was taken as RFC, unless analysis indicated a peak in the sensitivity profile elsewhere. It can be seen that there is indeed a tendency for cells with RFCs in the upper quadrants to possess a vector component in their direction preferences pointing upwards, while cells with RFCs in the lower half of the visual ficld often preferred downward movement.

This trend was then quantified by a linear-regression analysis using the least-squares method. Direction preference was analyzed as a function of the angle formed by the connecting line between RFC and area centralis and the horizontal meridian $\left(0^{\circ}\right.$ direction $)$. The regression line for all data points has a slope

\section{Table 2. Centrifugal bias of direction preferences as a function of} cortical layers

\begin{tabular}{cccc} 
Cortical & \multicolumn{2}{l}{$\begin{array}{l}\text { Axial direction } \\
\text { preference }\end{array}$} & Tayer \\
\cline { 2 - 3 }$<45^{\circ}$ & $>45^{\circ}$ & Total \\
\hline II-III & 25 & 24 & 49 \\
IV & 19 & 27 & 46 \\
V-VI & 14 & 6 & 20 \\
Total & 58 & 57 & 115
\end{tabular}

Numbers of cells are shown. Boxed values indicate the greater one of the two numbers in each line (see text). 
A

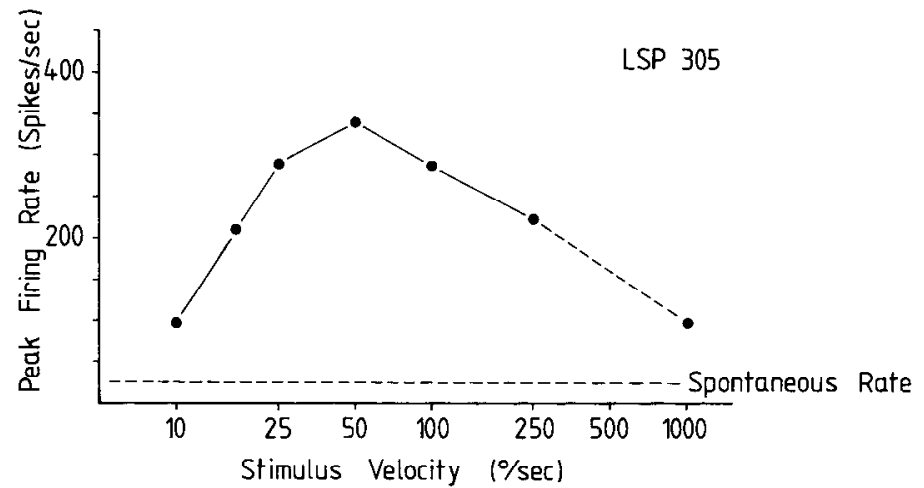

B

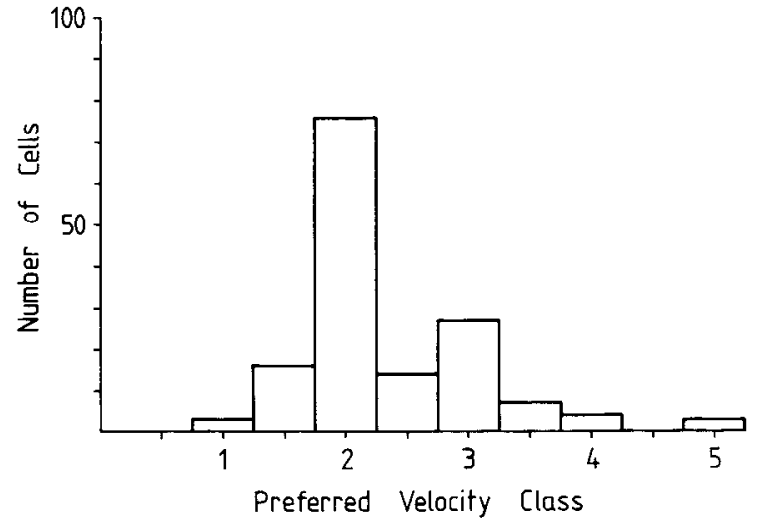

Figure 7. Velocity selectivity of LS cells. $A$, Example of a typical velocity tuning curve from a neuron in PMLS. The data point for $1000 \% \mathrm{sec}$ was extrapolated since this velocity could not be measured precisely. $B$, Distribution of velocity preferences in LS. See text for definition of classes. Most preferences fall into a range between $10^{\circ}$ and $40^{\circ} / \mathrm{sec}$. with different ADP in the different layers. A clear trend can be seen towards more cells with a centrifugal direction preference outside layer IV (see boxed values in Table 2).

\section{"Radial" and "circular" cells}

Summarizing this part of our results, a large class of cells in LS shows a preference for movement away from the area centralis (centrifugal direction bias). Cells with a preference for movement towards the area centralis (centripetal cells) are much less frequent (see Fig. 6). Together, centrifugal and centripetal units can be termed "radial" cells. Their direction preference falls within $\pm 22.5^{\circ}$ of the connecting line between the area centralis and the RFC. A second group is formed by cells whose direction preference falls within $\pm 22.5^{\circ}$ of the orthogonal to this line. These cells can be referred to as "circular." All other cells can be termed "residual." These new categories were chosen in order to facilitate the following statistical analysis, and they do not necessarily constitute functional categories.

\section{Velocity preferences}

For most cells, preferred velocity was classified on a 5-point scale, with classes corresponding to the following ranges of velocities: (1) $<5 \% \mathrm{sec}$, (2) $5-20 \% \mathrm{sec}$, (3) $21-50 \% \mathrm{sec}$, (4) $51-100 \%$ sec, and (5) $>100 \%$ sec. Intermediate classes were also used, especially when a precise value for optimal velocity was determined using PSTHs. Often it was difficult even then to decide on a preferred velocity, since cells responded almost equally to a very large range of velocities (see also Spear and Baumann, 1975). A rather typical example of a velocity tuning curve is plotted in Figure $7 A$. A distribution of preferred velocities is shown in Figure $7 B$ for all cells for which this could be determined ( 153 cells). It covers a wide range of velocities and peaks around $20 \%$ sec. 
Prcferrcd velocity was correlated with the cell's eccentricity (i.e., the distance of its RFC from the area centralis). A clear positive correlation was found for radial cells (Pearson $r=0.41$; $p<0.0001)$, whereas for circular $(r=0.34 ; p<0.02)$, and residual cells $(r=0.25 ; p>0.1)$, the correlation was weak or absent. The scatterplot for radial cells is shown in Figure 8.

Together with the present finding, the loosely retinotopic organization of PMLS (Palmer et al., 1978; see also "Visuotopic organization," above) would predict a negative correlation between preferred velocity and the depth of penetration (taken as the distance from the top of the sulcus). This correlation was weakly significant for radial cells $(r=-0.22 ; p<0.03)$ but not for circular cells $(r=-0.21 ; p<0.07)$ or residual cells $(r=$ $0.25 ; p>0.1)$.

Track analyses

Cluster analysis

The electrode penetrations usually passed through PMLS parallel to the cortical layers for some distance (see Fig. 1). Portions of such tangential tracks were reconstructed by plotting penetration depth (i.e., distance from the cranial surface) for radial, circular, and residual cells. Two examples are shown in Figure $9 \mathrm{~A}$. Some clustering of cells with similar characteristics along the tracks seems obvious from mere inspection.

In order to assess clustering more quantitatively, a statistical analysis was performed using conditional probabilities for finding the same or different types of cell within a given sampling distance $(100$ or 200 or $400 \mu \mathrm{m})$. The difference between the obtained and expected scores was calculated and the statistical significance tested with $\chi^{2}$ tests. More details of this analysis will be presented elsewhere (Von Grünau et al., in prep.). The results for a $100 \mu \mathrm{m}$ distance indicate that significant clustering ( $p<0.001)$ of cells did occur for the radial/circular stimulus characteristics. According to our histological reconstructions, this clustering appeared to be independent of the observed difference in laminar distribution of centrifugal units.

\section{Radial/circular preferences and retinotopic organization}

If we do not want to confound a clustering of "global" response properties, as suggested here, with a clustering of local properties, such as columns for local direction preference, it is necessary to relate our findings to the retinotopic organization. A clustering of radial $(R)$ and circular $(C)$ units could naturally be expected, if local direction preference changed smoothly while RF position remained constant within the visual field. Two tracks are shown in Figure 9, $B-E$. In each case, a continuous portion of the track was reconstructed, displaying the relative location of each cell with its preferred direction and its membership in the $\mathrm{R} / \mathrm{C}$ categories. Several clusters of $\mathrm{R}$ or $\mathrm{C}$ cells can be seen (Fig. 9, $B, D$ ) with a width of 300-400 $\mu \mathrm{m}$. Local direction preference changed fairly smoothly in a counterclockwise direction as the electrode proceeded further into the sulcus. Underneath, the locations of the cells' RFCs with respect to the visual areas and their changes with increasing depth are shown in Figure 9, $C$ and $E$. These tracks are good examples of a lack of a strictly retinotopic organization. In contrast to the ordcrly changes of local direction preference, RFC position changed rather erratically.

When we now compare the RFC position with the R/C categorization, we find clusters within the visual field in which cells belonged predominantly to either the $\mathrm{R}$ or $\mathrm{C}$ category. In some cases, it was quite clear that the return of RFC position to a

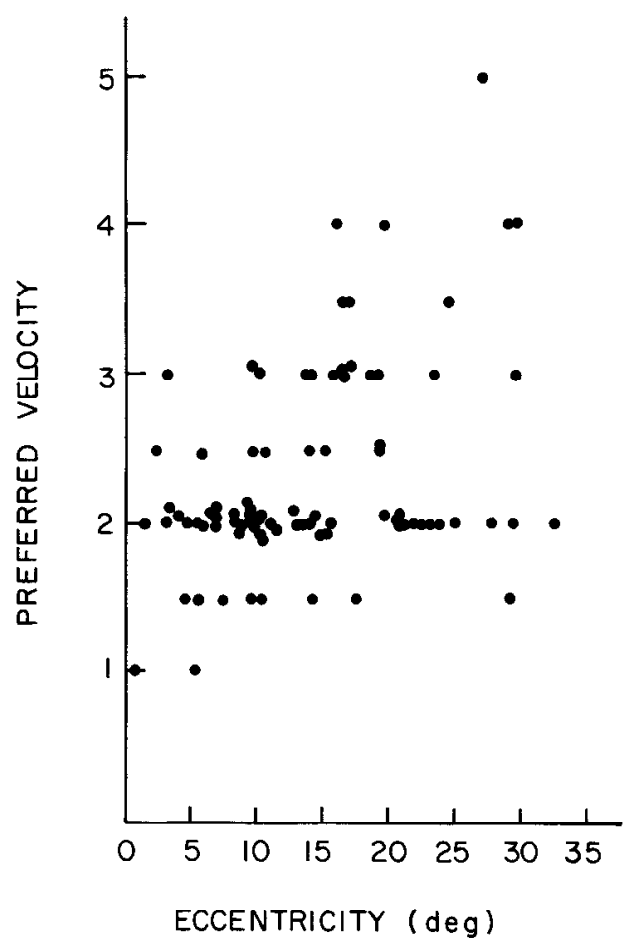

Figure 8. Preferred velocity as a function of eccentricity for "radial" cells. A positive correlation was found $(p<0.0001)$, cells with RFs closer to the area centralis preferring slower velocities and cells with more eccentric RFs responding best to higher velocities.

particular portion of the visual field also meant a change of "R/C"' category (e.g., cell 28 in Fig. 9C). Thus, the grouping of radial and nonradial, or circular, cells is not explained merely by a smooth change of local direction preference.

\section{Discussion}

Binocularity of cells in the lateral suprasylvian cortex Our findings confirm previous reports that most neurons in the lateral suprasylvian cortex are driven from both eyes (Spear and Baumann, 1975; Camarda and Rizzolatti, 1976). In addition, we have also shown that in more than half of the units (sometimes more than three quarters) there is a strong synergistic interaction between the 2 eyes. This results in a great enhancement of the response, sometimes several hundred percent, when both eyes are stimulated congruously.

Quite frequently, this binocular facilitation can even be demonstrated in cells that appear to be unresponsive or monocular on the basis of stimulation through either eye alone. Such AND cells are also present in the LP (Rauschecker and Friederichs, 1983; Rauschecker et al., 1984), which has reciprocal connections with the LS areas. Binocular AND units have occasionally been reported in other visual cortical areas as well (see Poggio, 1984). However, in area 17, because of the smaller RFs, eye alignment obviously has to be much more precise than in LS in order to demonstrate binocular interactions.

Prcvious studies have reported a much higher incidence of monocular neurons driven only by the contralateral eye (Hubel and Wiesel, 1969; Spear and Baumann, 1975). This may partly be because binocular facilitation was not tested rigorously. It might, however, also be explained by the fact that most of our cells had RFCs within the central $15^{\circ}-20^{\circ}$, very few having centers outside $30^{\circ}$. Hubel and Wiesel (1969) reported that they 


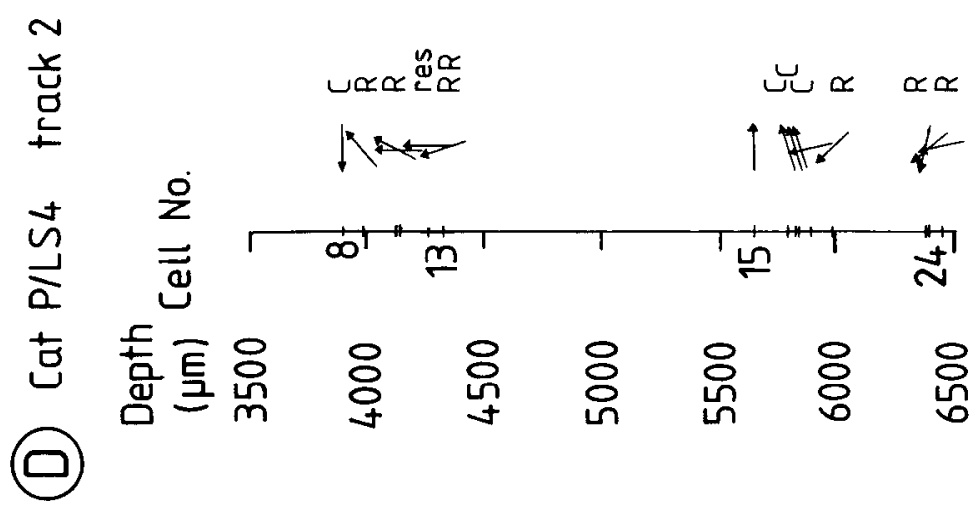

(4)

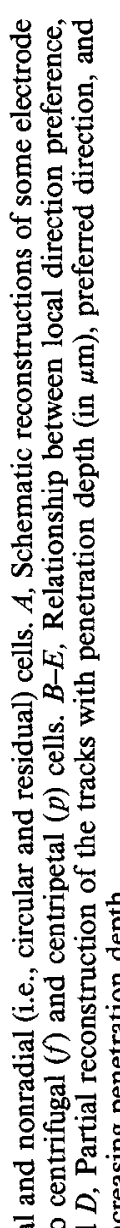

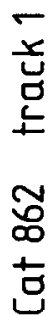

(9)
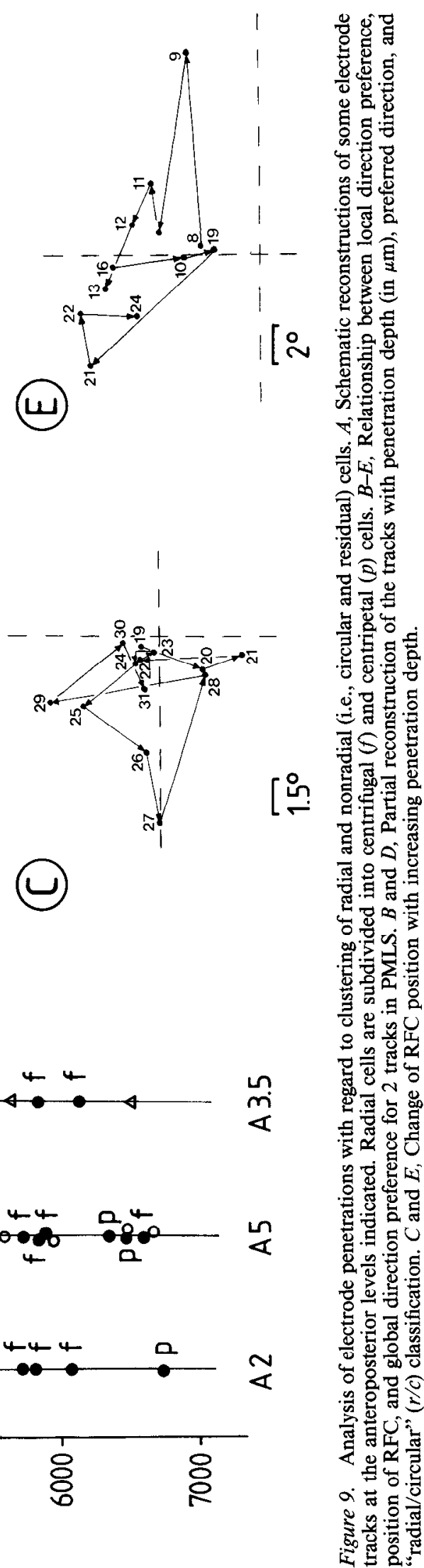

(大)

$$
\text { (யत) } 4+d \partial 0
$$

(U)

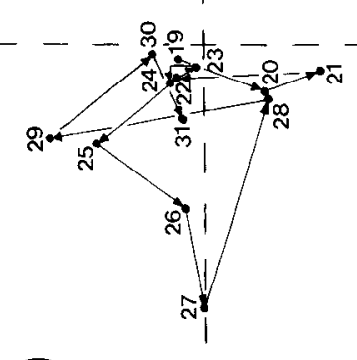

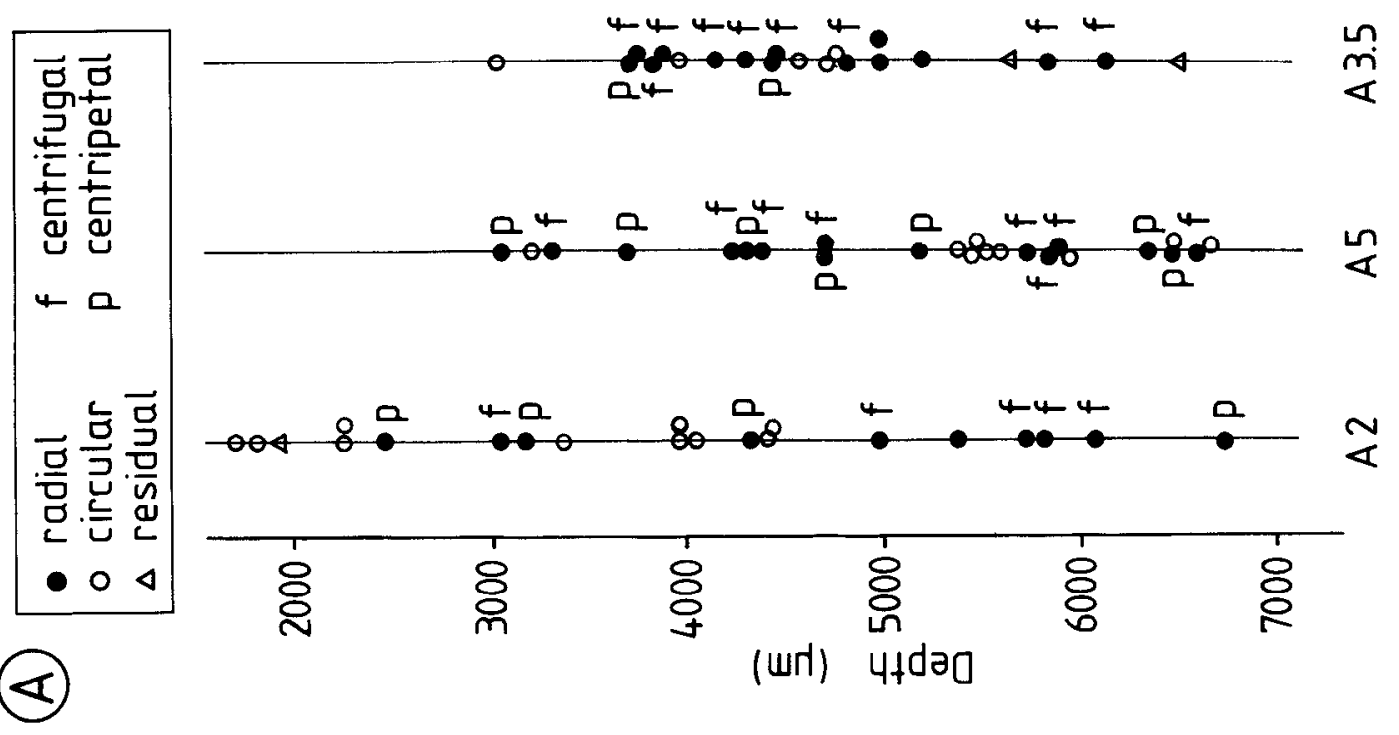



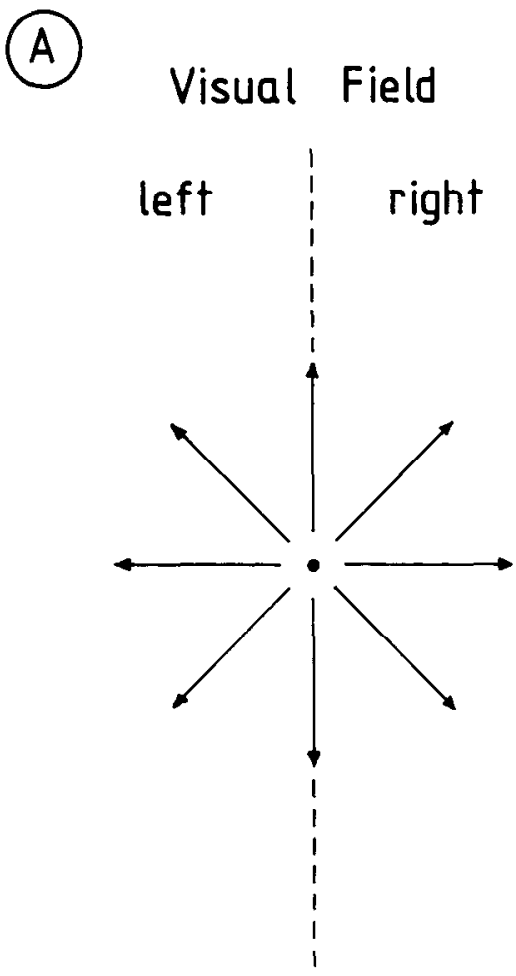

(B)

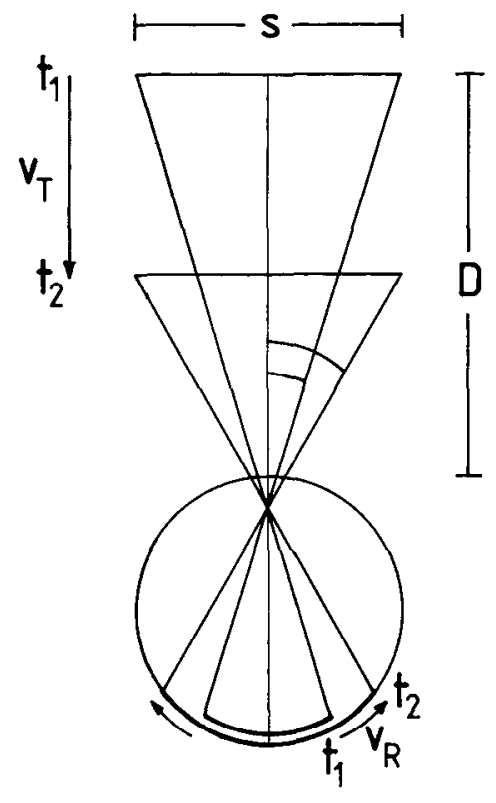

Figure 10. A, Expanding visual flow field generated by a looming stimulus. $B$, Schematic illustration of the dependence of retinal velocity $v_{r}$ on the stimulus velocity $v_{t}$, the size of the stimulus $s$, its momentary distance $D$, and eccentricity. found many fewer monocular cells within the central $10^{\circ}$. This was confirmed by Spear and Baumann (1975), and our own data are also consistent with it. This constitutes an example where a local single-unit response property depends on RF location within the visual field. Thus, binocularity seems to obey a global organization that is similar to the global organization of direction selectivity and velocity preference that we report here.

\section{Centrifugal bias of direction preference in LS cells}

The main new finding of this study is that a global organization of direction preferences exists in the cat's LS areas. Many cells, at least a certain subpopulation of them, respond best to movement away from the area centralis. Thus, direction preference for these cells depends on the location of their RFs within the visual field: Neurons with RFs in the upper half would often respond better to upward movement; those with RFs in the lower half to downward movement. Units whose RFs are situated along the horizontal meridian possess a higher probability of responding best to temporal movement. A trend for movement away from the midline has been mentioned in the studies by Hubel and Wiesel (1969), Spear and Baumann (1975), and, in particular, Camarda and Rizzolatti (1976), but this has not been quantified or analyzed in detail.

\section{Relation to subcortical structures}

A bias for horizontal preferred direction away from the midline has been reported for the SC (Straschill and Hoffmann, 1969; Sterling and Wickelgren, 1969; Dreher and Hoffmann, 1973; Rauschecker and Harris, 1983). This may also be part of a more general centrifugal bias of direction preferences similar to LS; it may have shown up as a horizontal bias, however, owing to a possible overrepresentation of the horizontal meridian (Feldon et al., 1970). Cortical ablation leads to partial loss of direction selectivity in the SC (Wickelgren and Sterling, 1969). Cells in layer V of LS are known to project to the SC (Holländer, 1974).
It is conceivable, therefore, that a centrifugal direction bias is imposed on the colliculus from LS.

The picture of a functionally homogeneous visual subsystem is completed by recent studies on the cat LP (Rauschecker and Friederichs, 1983; Rauschecker et al., 1984). In this main thalamic relay complex for the LS areas (Graybiel and Berson, 1981), which in turn receives reciprocal connections from layers $\mathrm{V}$ and VI of LS (Raczkowski and Rosenquist, 1983; Abramson and Chalupa, 1985), many single-unit response properties resemble those of cells in LS: Apart from binocular facilitation and broad velocity tuning, which have also been described by other studies (e.g., Chalupa et al., 1983), a pronounced direction selectivity of LP cells is found with a centrifugal bias similar to, if somewhat weaker than, in LS.

Finally, pyramidal cells in layer V of LS project to the pontine nuclei (Cohen et al., 1981), which in turn is an afferent structure for the cerebellum via the mossy fiber system. It is highly interesting, therefore, that a centrifugal bias among visual direction selective units in the cat's cerebellar cortex (vermis, lobules VI and VII) has been described previously (Vejbaesya, 1967, cited in Clarke, 1974). According to Chambers and Sprague (1955), the vermal zone of the cerebellum is particularly concerned with control of posture, muscle tone, locomotion, and equilibrium for the entire body. A similar trend towards centrifugal direction preference seems to be present also for the visual cells in the pontine nuclei (Baker et al., 1976).

\section{Relation to other cortical areas}

Direction selectivity in cells of the LS is reduced after lesions of area 17 (Spear and Baumann, 1979). On the other hand, cells projecting from the LP to LS are also direction selective (Rauschecker et al., 1984). It appears, therefore, that the specific properties of LS cells arise from an interaction of cortical and thalamic inputs.

A global organization of direction preference like that de- 
scribed here must require a rather sophisticated wiring of intracortical connections. The fact that the centrifugal direction bias was less pronounced in the input layer IV than in extragranular layers supports this conclusion. In order to generate this property, cells may have to communicate over long distances, which could be achieved by long-range excitatory connections similar to those described for area 17 (Gilbert and Wiesel, 1979, 1983). In addition, the global organization of direction preference in LS cells may be intimately connected with the topography of the LS areas (Palmer et al., 1978).

The centrifugal or radial organization of direction preferences in the LS areas is complemented by a radial organization of orientation preferences in neurons of the occipital cortex (areas 17-19; Leventhal et al., 1984). Thus, the global anisotropy of RFs in the 2 complexes is orthogonal to one another. This makes it tempting to postulate a complementarity of the 2 systems in visual processing, e.g., in figure-ground discrimination.

Perhaps the most interesting relation to other cortical areas can be seen in the studies by Motter and Mountcastle (1981) of area 7 in awake monkeys. These authors described cells having different direction preferences in different parts of their large RFs; within these subfields, these cells responded best to movement towards or away from the monkey's fovea. It is conceivable that a homologous cortical area exists in the cat with similar RF properties, in which every unit receives convergent input from a number of LS cells. On anatomical grounds, the anterior ectosylvian cortex could be a candidate for such an area (Mucke et al., 1982).

The converse question of whether a homologue in the monkey exists for the cat LS is still open. Certainly, the pronounced direction selectivity of cells in the middle temporal area (MT) (Maunsell and Van Essen, 1983) and its anatomical connectivity (Tigges et al., 1981) are rather suggestive features. There are recent reports of a whole complex of other areas with similar properties grouped in the vicinity of MT, which is also reminiscent of the LS complex (Van Essen and Maunsell, 1983; Ungerleider and Desimone, 1985).

\section{Functional significance of a centrifugal direction bias}

Two roles can be imagined for a neural system especially sensitive for visual stimuli moving away from the center of fixation. Both roles have to do with situations where the distance between a visual object and its fixating observer decreases. In this case, an optic flow field is generated that contains radial components pointing away from the center of gaze (Gibson, 1950; Regan and Beverley, 1979, 1982; Ullman, 1980; Hildreth, 1984).

In the case of an object moving towards a stationary observer looking straight ahead, the system is maximally activated if the object is moving on a trajectory within the central plane (e.g., if a stone or a ball threatens to hit the nose of the observer). A subsystem with a centrifugal direction bias could thus be very useful for the initiation of avoidance reactions. For such a case one might, in addition, expect individual neurons in LS to respond best to movement in 3-dimensional space. This has indeed been described in recent studies (Toyama and Kozasa, 1982; Toyama et al., 1985).

Alternatively, a visual subsystem like that described could subserve a role for tracking of a target during forward locomotion. Approach to a stationary or more slowly moving object could be guided by such a system, and, as a part of a servo mechanism maximizing the output of the system, it could help to maintain fixation on the object during tracking. Such situations are ubiquitous for animals like cats that depend on hunting for their survival.

\section{Processing of flow field information}

Velocity vectors in centrifugal directions are contained in an expanding flow field of visual motion, such as generated by forward locomotion or by an approaching object (Gibson, 1950). Backward locomotion or a receding object would cause a contracting flow field consisting of velocity vectors in centripetal directions. The fact that so many more neurons were found in LS with centrifugal than centripetal direction preferences might indicate the greater biological significance of an expanding flow field. However, it does not exclude the possibility that another area with centripetal preferences may exist. There is evidence that in the visual system of the fly morphologically and physiologically distinct neural subsets exist that process these different types of whole-field motion (Hausen, 1981).

In this context, the distribution of preferred velocity with respect to RF eccentricity is of interest (Fig. 10; see also Fig. 8). If a visual flow field is generated on the retina by a visual stimulus moving with constant speed, the velocity vectors on the retina vary with eccentricity (Gibson et al., 1955; Lee, 1976). Velocities are faster for more peripheral positions and slower for more central ones. In the center of the flow field velocity is zero. Indeed, we found a significant correlation for radial cells, such that neurons with more centrally located RFs preferred slower velocities than those with more eccentric ones. Though statistically significant, the increase of velocity preference with eccentricity was not as strong as might have been expected. The following 2 points have to be considered, however. There is usually a wide range of velocities to which individual neurons in LS respond (Spear and Baumann, 1975; Camarda and Rizzolatti, 1976). Also, at most eccentricities, a large number of cells can be found that have different preferred velocities, spanning almost the whole observed range. In this way, it is possible for LS to respond to many different flow fields produced by different speeds of locomotion.

\section{Clustering of neural subpopulations}

In most penetrations, electrodes were advanced in such a way that the tracks followed the sulcus rather closely, i.e., the electrodes advanced roughly parallel to the cortical layers. The results of the track analyses permit the conclusion that, with respect to the radial and circular (i.e., orthogonal to radial) direction properties, cells were not distributed evenly. On the contrary, radial and circular cells appeared in clusters of the same type, which had an extent of 300-400 $\mu \mathrm{m}$. Insufficient data are available at this time to define the clusters in terms of columns perpendicular to the cortical layers, though such an interpretation seems tempting.

This organization of PMLS into 2 spatially distinct neural populations occurs within the known loose retinotopic organization of PMLS (Spear and Baumann, 1975; Palmer et al., 1978). It is characteristic for this organization that more central points of visual space are represented closer to the fundus of the sulcus, while the periphery is represented closer to the top of the sulcus. Our results are consistent with this organization, showing a significant correlation between depth of penetration and eccentricity of RF position. Together with the obtained relation between preferred velocity and eccentricity, this also implies that proceeding along the sulcus toward the fundus one will en- 
counter cclls with increasingly slower preferred velocities, as observed here.

The position of a cell's RF within the visual field can be regarded as a local property of that cell. Its preferred direction of stimulus movement with respect to the visual field is another, independent, local property. We have found here that in LS these 2 properties do not seem to be independent but are linked to form the global properties of "radial" and "circular" direction preferences. With this type of organization, parts of the visual field are defined by the position of the RFs of cells with the same global property.

\section{Relation to figure-ground discrimination}

Another prominent RF property of LS cells described in detail by von Grünau and Frost (1983) is the directional double-opponent organization of their RFs. A possible function for this property, which has also been described for the pigeon's optic tectum, is in figure-ground discrimination, leading to the detection of object motion as opposed to self-induced motion of the whole visual field (Gibson, 1954; Frost and Nakayama, 1983; Frost, 1985). In view of our present findings, the following interpretation might be suggested. Locomotion of an organism through its environment, which consists of objects at various distances seen against a structured background, will result in relative motion of objects and background. The direction of local flow-field vectors will also depend on the distance between object and the organism. Objects that are closer than the plane of fixation will move against the direction of locomotion. Their velocity vectors will be larger than those of the background, which will move in the opposite direction. When the objects are farther away, however, they will move with the background. The latter condition is analogous to in-phase motion and will result in response inhibition of LS cells. The former condition corresponds to anti-phase motion and will lead to response enhancement. Thus, the function of LS cells may be the detection of objects that move relative to the background during locomotion. These objects will be closer, and therefore of greater importance, to the organism.

\section{References}

Abramson, B. P., and L. M. Chalupa (1985) The laminar distribution of cortical connections with the tecto- and cortico-recipient zones in the cat's lateral posterior nucleus. Neuroscience 15: 81-95.

Albus, K. (1975) A quantitative study of the projection area of the central and paracentral visual field in area 17 of the cat. I. The precision of the topography. Exp. Brain Res. 24: 159-179.

Baker, J., A. Gibson, M. Glickstein, and J. Stein (1976) Visual cells in pontine nuclei of the cat. J. Physiol. (Lond.) 255: 415-433.

Barlow, H. B., C. Blakemore, and J. D. Pettigrew (1967) The neural mechanism of binocular depth discrimination. J. Physiol. (Lond.) 193: 327-342.

Berman, N., and E. G. Jones (1977) A retino-pulvinar projection in the cat. Brain Res. 134: 237-248.

Berson, D. M., and A. M. Graybiel (1978) Parallel thalamic zones in the LP-pulvinar complex of the cat identified by their afferent and efferent connections. Brain Res. 147: 139-148.

Camarda, R., and G. Rizzolatti (1976) Visual receptive fields in the lateral suprasylvian area (Clare-Bishop area). Brain Res. 101: 427443.

Chalupa, L. M., R. W. Williams, and M. J. Hughes (1983) Visual response properties in the tectorecipient zone of the cat's lateral posterior-pulvinar complex: A comparison with the superior colliculus. J. Neurosci. 3: 2587-2596.

Chambers, W. W., and J. M. Sprague (1955) Functional localization in the cerebellum. I. Organization in longitudinal corticonuclear zones and their contribution to the control of posture, both extrapyramidal and pyramidal. J. Comp. Neurol. 103: 105-130.
Clare, M. H., and G. H. Bishop (1954) Responses from an association area secondarily activated from optic cortex. J. Neurophysiol. 17: $271-277$.

Clarke, P. G. H. (1974) The organization of visual processing in the pigeon cerebellum. J. Physiol. (Lond.) 243: 267-285.

Cohen, J. L., F. Robinson, J. May, and M. Glickstein (1981) Corticopontine projections of the lateral suprasylvian cortex: De-emphasis of the central visual field. Brain Res. 219: 239-248.

Dreher, B., and K.-P. Hoffmann (1973) Properties of excitatory and inhibitory regions in the receptive fields of single units in the cat's superior colliculus. Exp. Brain Res. 16: 333-353.

Feldon, S., P. Feldon, and L. Kruger (1970) Topography of the retinal projection upon the superior colliculus of the cat. Vision Res. 10: 135-143.

Frost, B. J. (1985) Neural mechanisms for detecting object motion and figure-ground boundaries contrasted with self-motion detecting systems. In Brain Mechanisms of Spatial Vision, D. Ingle, M. Jeannerod, and D. Lee, eds., Nijhoff, Netherlands.

Frost, B. J., and K. Nakayama (1983) Single visual neurons code opposing motion independent of direction. Science 220:744-745.

Gibson, J. J. (1950) The Perception of the Visual World, Houghton Mifflin, Boston.

Gibson, J. J. (1954) The visual perception of objective motion and subjective movement. Psychol. Rev. 61: 304-314.

Gibson, J. J. (1966) The Senses Considered as Perceptual Systems, Houghton Mifflin, Boston.

Gibson, J. J., P. Olum, and F. Rosenblatt (1955) Parallax and perspective during aircraft landings. Am. J. Psychol. 68: 372-385.

Gilbert, C. D., and J. P. Kelly (1975) The projections of cells in different layers of the cat's visual cortex. J. Comp. Neurol. 163: 81106.

Gilbert, C. D., and T. N. Wiesel (1979) Morphology and intracortical projections in cat visual cortex. Nature 280: 120-125.

Gilbert, C. D., and T. N. Wiesel (1983) Clustered intrinsic connections in cat visual cortex. J. Neurosci. 3: 1116-1133.

Graybiel, A. M., and D. M. Berson (1981) Families of related cortical areas in the extrastriate visual system: Summary of an hypothesis. In Cortical Sensory Organization, Vol. 2, C. N. Woolsey, ed., pp. 103120, Humana Press, Clifton, NJ.

Guedes, R., S. Watanabe, and O. D. Creutzfeldt (1983) Functional role of association fibres for a visual association area: The posterior suprasylvian sulcus of the cat. Exp. Brain Res. 49: 13-27.

Hausen, K. (1981) Monokulare und binokulare Bewegungsauswertung in der Lobula plate der Fliege [Monocular and binocular computation of motion in the lobula plate of the fly]. Verh. Dtsch. Zool. Ges. 74: 49-70.

Hildreth, E. C. (1984) The computation of the velocity field. Proc. R. Soc. London 221: 189-220.

Holländer, H. (1974) The origin of corticotectal projections in the cat. Exp. Brain Res. 27: 433-439.

Hubel, D. H., and T. N. Wiesel (1969) Visual area of the lateral suprasylvian gyrus (Clare-Bishop area) of the cat. J. Physiol. (Lond.) 202: 251-260.

Hubel, D. H., and T. N. Wiesel (1974) Uniformity of monkey striate cortex: A parallel relationship between field size, scatter, and magnification factor. J. Comp. Neurol. 158: 295-306.

Hubel, D. H., and T. N. Wiesel (1977) Functional architecture of macaque monkey visual cortex. Proc. R. Soc. London [Biol.] 198: 159.

Karnovsky, M. J., and L. Roots (1964) A "direct-coloring" thiocholine method for cholinesterases. J. Histochem. Cytochem. 12: 219-221.

Lee, D. N. (1976) A theory of visual control of braking based on information about time-to-collision. Perception 5: 437-457.

LeVay, S., and C. D. Gilbert (1976) Laminar patterns of geniculocortical projection in the cat. Brain Res. 113:1-10.

Leventhal, A. G., J. Keens, and I. Toerk (1980) The afferent ganglion cells and cortical projections of the retinal recipient zone (RRZ) of the cat's "pulvinar complex." J. Comp. Neurol. 194: 535-554.

Leventhal, A. G., J. D. Schall, and W. Wallace (1984) Relationship between preferred orientation and receptive field position of neurons in extrastriate cortex (area 19) in the cat. J. Comp. Neurol. 222: 445451.

Maciewicz, R. J. (1974) Afferents to the lateral suprasylvian gyrus of the cat traced with horseradish peroxidase. Brain Res. 78: 139-143.

Maunsell, J. H., and D. C. Van Essen (1983) Functional properties of neurons in middle temporal visual area of the macaque monkey. I. 
Selectivity for stimulus direction, speed, and orientation. J. Neurophysiol. 49: 1127-1147.

Mesulam, M. M. (1978) Tetramethyl benzidine for horseradish peroxidase neurohistochemistry: A noncarcinogenic blue reaction product with superior sensitivity for visualizing neural afferents and efferents. J. Histochem. Cytochem. 26: 106-117.

Motter, B. C., and V. B. Mountcastle (1981) The functional properties of the light-sensitive neurons of the posterior parietal cortex studied in waking monkeys: Foveal sparing and opponent vector organization. J. Neurosci. 1: 3-26.

Mucke, L., M. Norita, G. Benedek, and O. Creutzfeldt (1982) Physiologic and anatomic investigation of a visual cortical area situated in the ventral bank of the anterior ectosylvian sulcus of the cat. Exp. Brain Res. 46: 1-11.

Nakayama, K. (1985) Biological image motion processing: A review. Vision Res. 25: 625-660.

Newsome, W. T., R. H. Wurtz, M. R. Duersteler, and A. Mikami (1985) Deficits in visual motion processing following ibotenic acid lesions of the middle temporal visual area of the macaque monkey. J. Neurosci. 5: 825-840.

Palmer, L. A., A. C. Rosenquist, and R. J. Tusa (1978) The retinotopic organization of lateral suprasylvian visual areas in the cat. J. Comp. Neurol. 177: 237-256.

Poggio, G. F. (1984) Processing of stereoscopic information in primate visual cortex. In Dynamic Aspects of Neocortical Function, G. M. Edelman, W. E. Gall, and W. M. Cowan, eds., pp. 613-635, Wiley, New York.

Poulin, C., M. W. von Grünau, and J. P. Rauschecker (1984) Receptive field properties of single units in suprasylvian visual cortex (PMLS) suggest the processing of optical flow fields. ARVO Abstracts, Invest. Ophthalmol. (Suppl.) 25: 33.

Raczkowski, D., and A. C. Rosenquist (1983) Connections of the multiple visual cortical areas with the lateral posterior-pulvinar complex and adjacent thalamic nuclei in the cat. J. Neurosci. 3: 19431951.

Rauschecker, J. P., and A. Friederichs (1983) Visual information processing in the cat's LP-pulvinar complex. Behav. Brain Res. 8: 268.

Rauschecker, J. P., and L. R. Harris (1983) Auditory compensation of the effects of visual deprivation in the cat's superior colliculus. Exp. Brain Res. 50:69-83.

Rauschecker, J. P., and W. Singer (1981) The effects of early visual experience on the cat's visual cortex and their possible explanation by Hehb synapses. I. Physiol. (Lond.) 310: 215-239.

Rauschecker, J. P., M. W. von Grünau, and C. Poulin (1983) Convergent input to the cat's lateral suprasylvian visual cortex. Proc. Int Union Physiol. Sci. XV: 241.

Rauschecker, J. P., A. Friederichs, M. W. von Grünau, and C. Poulin (1984) A thalamo-cortical subsystem in the cat for the detection of expanding visual flow fields of motion. Soc. Neurosci. Abstr. 10:932.

Regan, D., and K. I. Beverley (1979) Visually guided locomotion: Psychophysical evidence for a neural mechanism sensitive to flow patterns. Science 205: 311-313.

Regan, D., and K. I. Beverley (1982) How do we avoid confounding the direction we are looking and the direction we are moving? Science 215: 194-196.

Reinoso-Suarez, F. (1961) Topographischer Hirnatlas der Katze für experimentalphysiologische Untersuchungen. Merck, Darmstadt.

Richards, W. (1975) Visual space perception. In Handbook of Perception, E. C. Carterette and M. P. Friedman, eds., pp. 351-386, Academic, New York.

Rizzolatti, G., and R. Camarda (1975) Inhibition of visual responses of single units in the cat visual area of the lateral suprasylvian gyrus (Clare-Bishop area) by the introduction of a second visual stimulus. Brain Res. 88: 357-361.

Rizzolatti, G., and R. Camarda (1977) Influence of the presentation of remote visual stimuli on visual responses of cat area 17 and lateral suprasylvian area. Exp. Brain Res. 29: 107-122.

Rosenquist, A. C., S. B. Edwards, and L. A. Palmer (1974) An au- toradiographic study of the projection of the dorsal lateral geniculate nucleus and the posterior nucleus in the cat. Brain Res. 80: 71-94.

Rosenquist, A. C., L. A. Palmer, S. B. Edwards, and R. J. Tusa (1975) Thalamic efferents to visual cortical areas in the cat. Soc. Neurosci. Abstr. 1: 53.

Spear, P. D., and T. P. Baumann (1975) Receptive-field characteristics of single neurons in lateral suprasylvian visual area of the cat. $\mathbf{J}$. Neurophysiol. 38: 1403-1420.

Spear, P. D., and T. P. Baumann (1979) Effects of visual cortex removal on receptive field properties of neurons in lateral suprasylvian visual area of the cat. J. Neurophysiol. 41: 31-56.

Sterling, P., and B. G. Wickelgren (1969) Visual receptive fields in the superior colliculus of the cat. J. Neurophysiol. 32: 1-15.

Straschill, M., and K.-P. Hoffmann (1969) Functional aspects of localization in the cat's tectum opticum. Brain Res. 13: 274-283.

Symonds, L. L., A. C. Rosenquist, S. B. Edwards, and L. A. Palmer (1981) Projection of the pulvinar-lateral posterior complex to visual cortical areas in the cat. Neuroscience 16:1995-2020.

Tigges, J., M. Tigges, S. Anschel, N. A. Cross, W. D. Letbetter, and R. L. McBride (1981) Areal and laminar distribution of neurons interconnecting the central, visual cortical areas 17, 18,19 and MT in the squirrel monkey (Saimiri). J. Comp. Neurol. 202: 539-560.

Toyama, K., and T. Kozasa (1982) Responses of Clare-Bishop neurones to three-dimensional movement of a light stimulus. Vision Res. 22: 571-574.

Toyama, K., Y. Komatsu, H. Kasai, K. Fujii, and K. Umetani (1985) Responsiveness of Clare-Bishop neurons to visual cues associated with motion of a visual stimulus in three-dimensional space. Vision Res. 25: 407-414.

Tusa, R. J., L. A. Palmer, and A. C. Rosenquist (1978) The retinotopic organization of area 17 (striate cortex) in the cat. J. Comp. Neurol. 177: 213-236.

Ullman, S. (1980) The interpretation of three-dimensional structure from motion. Proc. R. Soc. London [Biol.] 203: 405-426.

Ungerleider, L. G., and R. Desimone (1985) Multiple visual areas in the caudal superior temporal sulcus of the macaque. Soc. Neurosci. Abstr. 11: 1012

Updyke, B. V. (1977) Topographic organization of the projections from cortical areas 17,18 and 19 onto the thalamus, pretectum and superior colliculus in the cat. J. Comp. Neurol. 173: 81-122.

Updyke, B. V. (1981) Projections from visual areas of the middle suprasylvian sulcus onto the lateral posterior complex and adjacent thalamic nuclei in cat. J. Comp. Neurol. 201: 477-506.

Van Essen, D. C., and H. R. Maunsell (1983) Hierarchical organization and functional streams in the visual cortex. Trends Neurosci. $6: 370$ 375 .

Vejbaesya, C. (1967) Studies on the connections of the visual system. Ph.D. thesis, University of Edinburgh.

von Grünau, M. W., and B. J. Frost (1983) Double-opponent-process mechanism underlying RF-structure of directionally specific cells of cat lateral suprasylvian visual area. Exp. Brain Res. 49: 84-92.

von Grünau, M. W., C. Poulin, and J. P. Rauschecker (1983) Binocular facilitation in lateral suprasylvian visual area of normal and strabismic cats. Proc. Int. Union Physiol. Sci. XV: 446.

Wickelgren, B. G., and P. Sterling (1969) Influence of visual cortex on receptive fields in the superior colliculus of the cat. J. Neurophysiol. 32: $16-32$.

Woolsey, C. N. (1981) Cortical Sensory Organization. Vol. 2. Multiple Visual Areas, Humana Press, Clifton, NJ.

Zeki, S. M. (1978) Functional specialization in the visual cortex of the rhesus monkey. Nature 274: 423-428.

Zeki, S. M. (1980) The response of cells in the anterior bank of the supcrior temporal sulcus in macaque monkeys. J. Physiol. (Lond.) 236: $549-573$.

Zumbroich, T., and C. Blakemore (1985) Direction-selectivity and orientation-selectivity in the pustero-lateral suprasylvian areas of the cat's cortex. Neurosci. Lett. Suppl. 22: S304. 